\title{
Evaluation of the use of Real-Time 3D Graphics to Augment Therapeutic Music Sessions for Young People on the Autism Spectrum
}

\author{
John McGowan \\ School of Computing, Edinburgh Napier University, UK, j.mcgowan@ napier.ac.uk \\ Iain McGregor \\ School of Computing, Edinburgh Napier University, UK, i.mcgregor@napier.ac.uk \\ Gregory Leplatre \\ School of Computing, Edinburgh Napier University, UK, g.leplatre@ napier.ac.uk
}

\begin{abstract}
The present research evaluates the effectiveness of CymaSense, a real-time 3D visualisation application developed by the authors, as a means of improving the communicative behaviours of autistic participants through the addition of a visual modality within therapeutic music sessions. Autism spectrum condition (ASC) is a lifelong neurodevelopmental disorder that can affect people in a number of ways, commonly through difficulties in communication. A multi-sensory approach within music sessions encourages people with ASC to engage more with the act of creating music, and with the therapists, increasing their level of communication and social interaction beyond the sessions.

This paper presents a study evaluating the use of CymaSense within a series of therapeutic music sessions, and a follow-up series of semi-structured interviews. Eight adults with ASC participated in 12 sessions using a single case experimental design approach over a total period of 19 weeks. Using qualitative and quantitative data, the results show an increase in communicative behaviour, for both verbal and nonverbal participants, resulting from the use of CymaSense. Qualitative feedback from interviews provided insight into the factors that contribute to the successful use of the application, as well as aspects that could be improved.
\end{abstract}

\section{CCS Concepts}

- Human-centered computing • Empirical studies in accessibility • Accessibility systems and tools • Empirical studies in visualization

\section{KEYWORDS}

Autism, Music Therapy, Sound Visualisation, Interactive Audio-Visual, Assistive Technologies, MultiSensory Environments, Cymatics.

\section{INTRODUCTION}

Defined by the American Psychiatric Association, Autism Spectrum Disorders (ASD), also known as Autism Spectrum Condition (ASC), are characterised through impaired development in social interaction, communication and repetitive behaviours and interests [1]. Interventions for autism have four broad categories, including behavioural, speech and language therapies, neurosensory therapies, and biochemical interventions [2]. The most widely recommended, applied behavioural analysis (ABA), is considered the most effective [3][4][5]. However, critics have argued that ABA creates additional challenges on the learner relating to their ability to understand vocal stimuli and respond with vocalisations of their own, which can be difficult for many people with ASC [6]. Bredek et al. suggest ABA can also be restrictive to the individual's freedom of expression, by using commonly used forms of response modifications like picture communication systems and pre-written words [6]. Music therapy can provide a non-verbal means of communication [7], and people with ASC are widely reported to respond positively to music therapy interventions that incorporate active and improvisational techniques [8]. A level of predictability, and repeatability within musical structure offers people with ASC a channel of communication through which to express themselves, which can result in a number of benefits. Brown comments that musical structures exhibit similarities with both the creative and organisational elements required for functional interaction with the world for a person with autism [9]. Lim states that the inherent structure of music stimuli and intact capacity of pattern perception and production in people with ASC, 
has a positive effect on speech production when used as a stimulus with ABA [10]. Not all of the successes of music therapy are easy to quantify however, as they can integrate medical, educational, sociological, psychological and musicological discourses within their practices [11]. This may be due to the how music therapies are evaluated, and the heterogeneity of autistic groups - the nature of the spectrum condition being that no two groups or individuals have the same abilities or requirements [12]. Consequently, this can lead to a lack of randomised controlled trials that can easily be run with groups of people with ASC, with many funding bodies asking for longer term objective studies to back up existing case histories [11]. Music therapy is often considered an effective intervention for young people experiencing social, emotional or behavioural difficulties. However, this assumption lacks empirical evidence and more research needs to be conducted, particularly within more naturalistic settings [13][14]. Nonetheless, individual case studies continue to back the validity and success of music therapy techniques [15].

Since the early 2000s there has been an exponential growth in the use of electronic assistive technologies supporting research and the development of people with ASDs in social, communicative, language and educational domains [16]. Music and arts therapists often use electronic technology within their practice to stimulate the senses of people with ASC, and to allow them the creative freedom to express themselves. Simple iPad apps, providing the experience of playing a digital musical instrument, through to sophisticated music production tools are available, and are used to a limited extent within current practice [17]. Computers have been shown to provide a certain amount of predictability and stability for people on the autism spectrum, creating an attractive environment due to the lack of human contact and stress involved in reading emotional cues from verbal, non-verbal cues and body language [18]. While developments in mobile and motion capture devices like the Microsoft Kinect [19], has increased the use of multimedia devices within the public domain. However, not all therapists are sufficiently well informed about, or proficient in the use of, modern technologies and the effective use of assistive technologies may be limited. Previous studies have shown beneficial use of interactive multimodal systems for people with ASC. The Reactable tangible user interface (see Figure 1) visualises synthesised sound as animated 2D graphical connections between modular blocks [20]. Gestural systems like SensoryPaint use sound to highlight animated movement [21]. Interactive Surfaces, like BendableSound, use tactile, visual and audio feedback to engage people with ASC [22] (See Figure 1). Hunt et al.[23] noted that in some cases visuals may distract people with ASC from the music, whereas in other situations the visuals may be a way in to someone who was previously struggling to become engaged with the music. Evaluation of multimodal environments for people with ASC [24] have suggested that music therapy could be made more engaging if the musical channel of communication it aims to open, between therapist and client, were augmented by a visual modality.

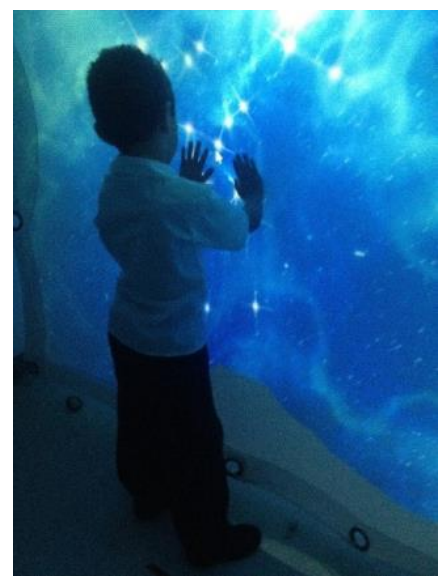

Figure 1: A person with ASC interacting with BendableSound [22].

CymaSense is an interactive multimodal interface that generates real-time 3D visual stimuli based on 
Cymatics (see Figure 2), designed to improve the communicative behaviours of people with ASC [25]. In this paper, we present a study in which CymaSense was used to augment therapeutic music sessions involving adults with ASC. The study, which involved eight young adults with ASC, intended to assess the hypothesis that use of an audio-visual tool within therapeutic music sessions, such as CymaSense, could improve communicative behaviours for people with ASC.

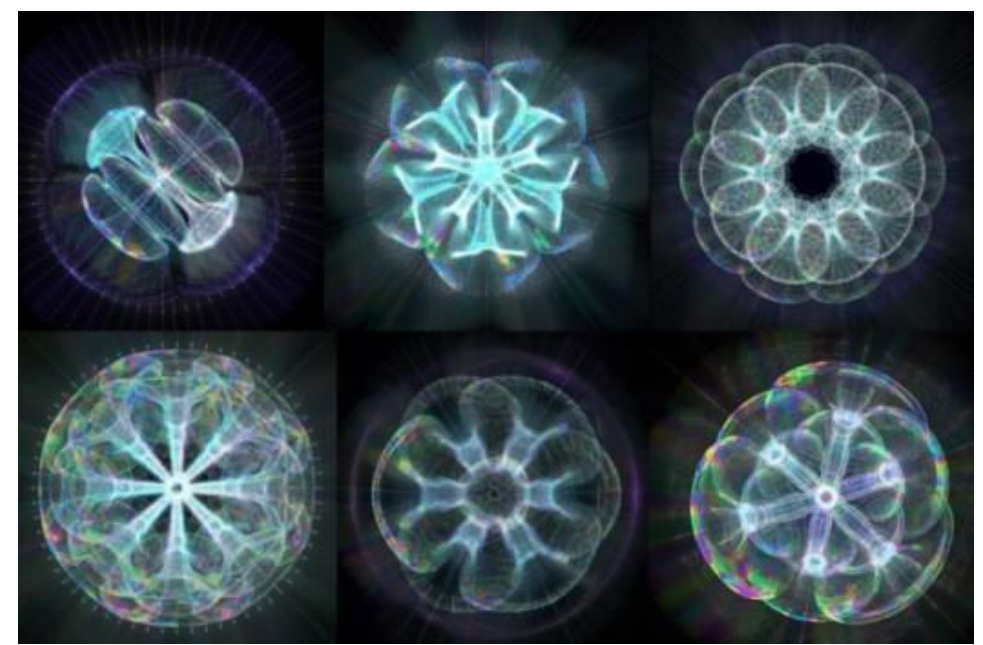

Figure 2: Example of Cymatic shapes generated by CymaSense. Single shapes can be projected onto walls or onto the underside of an interactive table, based on volume, pitch and timbre (see Figure 7).

This article is an expanded version of a conference paper [26], presented at ASSETS'17. The paper focused on results from an initial study where eight adults with ASC participated in an 8-week period using a single case experimental design approach. The study used qualitative and quantitative methodological tools for analysis within and beyond the therapy sessions. One point of discussion related to analysis of the data, where an experimental $A B$ design may not be as strong as one where the intervention is withdrawn and then reintroduced [27]. Reichow et al. commented that the $A B$ design, which does not involve the repeated introduction of the independent variable, may not be sufficient to demonstrate that the intervention was effective. Others argue that the ABA design raises ethical issues regarding potential harm to participants' if the intervention is removed too soon [28] (see section 4.7). This version addresses that point by detailing a follow-up study of 4 weeks, after a 7-week gap in music sessions, which also incorporated a one week withdrawal phase. The study can now be viewed as a 12week study with additional data, for further validation of the original findings.

Additionally, following completion of the music sessions, a series of four semi-structured interviews were conducted with parents of participants and the music tutor. The interviews were designed to gather background information on participants' behaviour, auditory and visual preferences, and current use of technology, in order to further assess the potential benefits of CymaSense, and to identify requirements for further development. The completed study can be viewed as three phases: phases 1 and 2 are the 8week and 4-week music sessions (section 4); phase 3 is the follow-up interviews (section 5). The phases were deliberately compartmentalised, as firstly the research focused on what participants were doing in the sessions in phases 1 and 2, then on what the consequences of those sessions were in the long term in phase 3.

\section{RELATED WORK}

This section discusses the challenges associated with Autism Spectrum Condition and some of the multimodal interventions employed to counter these challenges. In addition, effective methods of evaluating these interventions are discussed.

\section{I Background to autism}

Autism Spectrum Condition (ASC), also known as Autism Spectrum Disorder (ASD), is a lifelong neurodevelopmental condition defined as persistent deficits in social communication and social 
interaction across multiple contexts, restricted, repetitive patterns of behavior, interests, or activities [1]. A 2014 study by the Centres for Disease Control found that the condition affects one child in every 68, and has encouraged health professionals to consider ASC as a critical and urgent public health concern [29]. Research has shown that autism is a condition where promising strategies are being applied to identify common genetic risk variants [12]. However, not all of its genetic or biological signature has yet been identified [30].

People with autism can experience complications in tactile, visual and auditory processing, and may not be not fully conscious of the amount of control they can exert over their environment and obtain a coherent response, even when it is they themselves who are responsible for the changes [31]. Higher functioning people with ASC also have the capability to reflect on the implications of their diagnosis for everyday interactions, leaving them prone to secondary psychiatric disorders [32]. The isolating nature of this condition has shown higher rates of anxiety and depression, regardless of intellectual and linguistic abilities [33], prompting researchers to find solutions to a condition where relatively little is known concerning its causes [34]. Much of early and current research has focused on behavioural approaches to intervention, which can provide success in terms of treating symptoms, but does not address the core emotional expression, regulation and recognition of people with ASC [35]. Issues of low self-esteem, anxiety and attitudes towards relationships with peers can create additional physical illnesses and mental health issues [36]. Support for people on the autism spectrum seems to be lacking for both the adolescent and adult communities, partly due to the rising numbers of people being diagnosed with ASC at the beginning of the 21st century [7]. It has even been noted that there exists more support for parents of autistic children than for adults with ASC [35]. Feedback from a study by Pellicano et al.[37] shows that the causes of autism are creating the most interest as opposed to the ways in which help can be generated for those who need it. Additionally, the nature of decision-making, whereby autistic people, their family members and practitioners are rarely involved in the decision-making processes that shape the research and applications. Fabri and Andrews [38] confirm this lack of consultation with young autistic adults regarding the design of new technology for their use.

\subsection{Multimodal interventions}

Music therapists currently use both traditional methods and assistive technologies as tools to support their practice as an effective approach against the challenges of autism. Music therapy is considered an effective approach for addressing language and communication skills for people with ASC [39][40][41][42]. Therapeutic interventions involving music have shown enhanced social interaction with peers [43][44], as well as enhanced peer interactions [45]. They have improved verbal communication [46][40][10] and social greeting routines [47]. Music-based interventions have enhanced self-esteem [46], reduced anxiety and improved mood [48][49]. They have also increased eye contact [44][50], enhanced cognitive social skills [51][52] and improved joint attention behaviours [53][54][50]. An autism-based study in 2012 indicated that functional processing systems were more effectively engaged for song than for speech [55]. A more recent study in 2018 provided the first evidence that 812 weeks of individual music intervention can improve social communication and functional brain connectivity in children with autism [56]. As people on the autism spectrum are known to have difficulties in communication and expression of emotions through language, music therapy can provide them with a non-verbal means of interaction [57][58]. In addition to traditional acoustic instruments and use of the human voice, music and arts therapists continue to embrace technology within their practice to achieve a greater sense of agency and stimulate the senses of people with ASC. This can include: electronic interfaces like the iPad or Launchpad [59]; existing assistive technologies and tangible user interfaces (TUI) like the Skoog [60] or Reactable [20], which have been shown to improve social interaction and play in people with ASC through a shared space [61]. Research has demonstrated that sensory integration therapy encouraged development of independence amongst people with ASC [62].

Multimodal applications and technologies have been employed as a means of encouraging bodyawareness and independence in people with ASC. Ringland et al. [21] developed SensoryPaint, a multisensory application for children with ASC, focusing on body awareness and sensory stimuli. The authors employed a natural user interface (NUI) approach negating the need for technological tools or training. The study showed that the use of multi-modal and NUIs aided in balancing children's attention between 
their own bodies and sensory stimuli, in order to augment existing therapies, and promote socialisation. Villaroman et al. [63] identified NUIs as a more intuitive way for people to interact with computing devices compared to typical graphical user interfaces. They employed a Microsoft Kinect [19] sensor to facilitate interaction with various applications through gestural interaction, leading to the application of humanoid robots using Kinect to improve joint attention and imitation in people with ASC [64]. Another interactive system is the MEDIATE environment designed for children with severe autism [31]. The authors argued that a lack of a sense of agency within an autistic child could be counteracted via the use of a cause-and-effect interactive environment that mirrored the movements of the ASC child's body in a variety of ways. The initial phase of tests was successful, however, Parés et al. commented that as the technology was not portable, it was thus not accessible on a regular basis for potential participants. However, with 3D camera technologies in handheld devices this could become portable.

For people with ASC, comprehension of cause-and-effect can be problematic due to issues with sensory impairment [65], and previous research has addressed this through audio-visual means. Therapeutic approaches involve teaching children how to combine sensory integration and body awareness therapies, known as Multi-Sensory Environments (MSE), which can aid in the attainment of set therapeutic goals. Studies involving MSEs have demonstrated the efficacy of this approach [21], but have not been widely adapted for use within music therapy sessions. Cibrian et al. successfully facilitated music therapy sessions using their BendableSound prototype which uses animation and sound in conjunction with a fabric-based interactive surface [22][66]. The system, which back-projected scenes onto fabric and responded to touch in three dimensions, was designed to encourage attention and motor development, but is somewhat restricted to the playing of the interactive surface itself, rather than providing the user with a selection of playable instruments or surfaces [22]. Hailpern's work [67] focused on encouraging visualisation of non-speech vocalisations by people with ASC through a number of alternative visual forms, including falling and spinning visualisations. The CHIMELIGHT system, designed to maintain engagement for children with neurodevelopmental disorders during music therapy sessions, has seen potential changes in positive behaviours, through the use of contingent visual feedback based on realtime motion analysis [68]. Current audio-visual applications that demonstrate simple cause-and-effect take many forms, from: web-based visualisers [69]; stand-alone applications that link to audio and media players [70]; iPad apps [71]; and VJing software for use in art installations and public performances. However, the majority of these use arbitrary visualisations of sound based on the amplitude of the audio, and are not specifically designed for people on the autism spectrum.

A common contradictory misconception between autism and creativity, generated by those external to autism and therapy, can be overcome through subtle interplay and a space that allows meaningful participation. In designing creative spaces for people with ASC, Frauenberger and colleagues [72] highlighted that by combining well-known activities with familiar, but slightly modified elements, they found that participants felt free to appropriate them in original ways. They employed a Play Partner and an Active Observer, which contributed to facilitating a creative process. Lazar and colleagues [73] discussed ways to empower adults with cognitive impairments through art therapy via the Third Hand technique, where the therapist recognises and enables the skills of the client, builds on previous sessions and provides support. Augmenting the auditory modality with real-time visual feedback may be an effective means of strengthening a sense of causality within a music therapy scenario. In order to achieve this goal, a suitable real-time music visualisation system is required.

\subsection{Evaluation of Multimodal Interventions}

Single subject case design [74] has been used by a number of Music Therapy case studies and within related intervention studies for Autism [75][27][20]. It can allow changes in the relationship with the therapist and with other family members to be detailed using a variety of research methods. Changes in emerging phenomena, such as new intervention, can be detailed and new models created. The structure of the design is dependent on the individual participants; however, in general a baseline stage (A) is carried out over a period of several sessions. Following this, an intervention stage (B) introduces the intervention to be tested. Subsequent permutations and combinations may include no intervention baseline (BA), the reintroduction of a withdrawal session (ABA - known as basic withdrawal), which can be free time for participants to do as they will, reversal design (BAB), or the introduction of a (C) 
stage etc. (ABAC). A reversal design was successfully used by Edgerton [76] and others in the evaluation of interventions with autistic children [77][78][79]. Geist and Hitchcock [75] point out that with a secondary demonstration of an effect of intervention (through reversal design), alternative explanations such as regression to the mean, history, maturation, history etc. become far less plausible explanations for the change in behaviour of autistic participants.

\section{DESIGN OF CYMASENSE}

CymaSense is an interactive application that generates 3D visualisations in response to real-time acoustic and electronic audio input (See [25] for a detailed presentation of the tool). Processed audio or MIDI input is transformed into translucent 3D Cymatic shapes and projected onto a screen or interactive surface (Figure 2). Changes in volume affect the scale of the shapes being presented. Variations in timbre modify the surface qualities of the shapes being visualised. Changes in pitch determine which Cymatic shape (out of 12) is chosen, as well as colour lightness of shape. A user interface allows background and Cymatic shape colour choices to be made. A single-user version displays a single set of Cymatic shapes in the centre of the screen, while a 2-user version displays shapes side-by-side on screen in a manner commonly utilized in split screen video games [80].

High definition Cymascope images of individual frequencies were used as templates for the creation of twelve 3D Cymatic shapes, relating to each of the semitones within a musical octave. The MIDI and audio inputs are analysed in real-time using Cycling'74 Max [81]. Relevant data (amplitude, pitch, harmonic content, velocity, pitch bend) is transmitted using the Open Sound Control (OSC) to the Unity games engine in which the visualisation is generated. CymaSense comprises (1) an interface to control audio input and visual output for single or multi-user interaction and (2) a separate output screen (see Figure 5 in section 4.2)

\section{I Audio-visual mapping}

The mapping between audio and visual attributes is based on audio visual associations validated by previous studies [82]. However, the novelty of the visualisation paradigm implemented in CymaSense also afforded experimentation with the less obvious aspects of the mapping, which included mapping pitch to shape, and timbre to surface quality of shape:

- Amplitude to scale of Cymatic shape and particle size - mapping amplitude to scale is commonly referred to in literature [83].

- Pitch to Cymatic shape - this is consistent with Cymatic shape behaviours observed. The 3D shapes created were inspired by Cymascope reference images [84].

- Pitch to Colour Lightness - lightness of colour is altered by MIDI note or microphone frequency, implementing a pitch to lightness relationship, referred to in synesthesia and cross modality literature [85]. The higher the pitch, the lighter the visual component. This aids in differentiating the same Cymatic shape over several octaves.

- Timbre to Cymatic shape surface quality - timbre is considered the most difficult characteristic of tone to describe [86]. It is also referred to as a potentially useful tool in audio-visualisation by therapeutic practitioners. Colour is commonly associated with timbre in audiovisual mappings, but colour was also being used for as an additional means to differentiate the Cymatic shapes, and thus the audio pitch, in the application. Therefore, it was decided to experiment with surface qualities as a means of representing the spectral qualities of a sound. The Cymatic shapes generated for a given frequency were modified using a 3D morphing technique as follows: the shapes of bright sounds were made to appear sharper, while dark sounds were transformed to appear more rounded.

\subsection{Additional Interface Options}

The following functionalities were implemented in CymaSense (please refer to [25] for additional details):

- Cymatic shape colour and background colour choice: colour was identified in literature [87] and through interviews with therapists, as key to empowering people with ASC, regarding making their own choices. Each CymaSense shape comprised an external shell and two sets of animated particles. 
Colour assignment to both the shell and particles are possible to allow a variety of colour combinations. User selection of: Cymatic shape outer material colour; main particle colour; internal particle colour; and background colour have been made available directly from the interface.

- Cymatic shape rotation: through observation of Cymatic shapes created in water, it has been noted that in addition to changes in shape dependent on frequency, subtle rotations occur. A simple on/off button for no or random rotation values was deemed sufficient for the initial prototype where a change in frequency or MIDI note triggers a random quaternion rotation on all three axes between a value of -1 and 1, providing immediate but subtle audio-visual feedback. Video Figures [88, 89, 90, 91] demonstrate CymaSense in use by participants of the study presented in section 4.

\section{METHOD FOR MAIN STUDY}

The evaluation consisted of three phases presented over two sections (4 and 5), which each have their own associated method. The method for the main study (Section 4) comprises phase 1 and phase 2. Phase 1 was an 8-week study conducted with 8 participants previously presented in the conference paper [26]. Phase 2 involved a further 4 weeks of therapeutic music sessions conducted after a 7 -week break, during which the participants did not attend any other sessions. The 7-week break was the required amount of time requited to arrange and organise the follow-up sessions with the same participants. The method for the follow-up interviews presents phase 3 of the study, which consisted of interviews with parents/guardians and the music tutor and is presented in Section 5.

This section presents Phases 1 and 2 of the evaluation carried out with TouchBase, a centre run by Sense Scotland charity [92] for people with a variety of disabilities, including autism. The evaluation was designed to test whether the use of CymaSense in therapeutic music sessions could improve communication. The following hypotheses were tested:

(1) The use of CymaSense within therapeutic music sessions can lead to an increase in communicative behaviours during the sessions.

(2) The use of CymaSense will lead to changes in the communicative, social and musical behaviours of the autistic participants observable by parents, care workers or tutors at the conclusion of the study.

\section{I Participants}

The Sense Scotland (2019) music tutor has been running therapeutic sessions and working with people with additional support needs since 1999. He has developed a range of ideas to enable people with disabilities to find alternative ways of communication and self-expression through improvisational musical approaches, and has worked previously with all but one participant in the present study. His usual practice is similar to traditional music therapy and involves using a variety of acoustic, electronic instruments and voice, using structured and improvisational techniques tailored to individual participants' needs. The tutor was not previously involved in the development of CymaSense.

Six adult males and two adult females, who have been clinically diagnosed as being on the autism spectrum, were recruited as participants from Scottish Autism [94] and Sense Scotland [92] for the study. Due to ethical concerns, no other information regarding health concerns was requested. Table 1 provides an overview of the participant details. 
Table 1: Overview of participant details

\begin{tabular}{|c|c|c|c|c|}
\hline Participant & Age & Communicative Abilities & Musical Abilities & Comments \\
\hline P1 & $\begin{array}{l}\text { Late } \\
\text { teens }\end{array}$ & $\begin{array}{c}\text { Non-verbal skills, uses facial } \\
\text { expression, gesturing and pictorial } \\
\text { methods }\end{array}$ & $\begin{array}{l}\text { Preference for } \\
\text { percussion }\end{array}$ & $\begin{array}{c}\text { Prone to verbal outbursts } \\
\text { and body rocking }\end{array}$ \\
\hline $\mathrm{P} 2$ & Late 20 s & $\begin{array}{c}\text { Non-verbal skills, uses facial } \\
\text { expression, gesturing, body } \\
\text { language and objects of reference }\end{array}$ & $\begin{array}{l}\text { Turn-taking rhythmic } \\
\text { activities on the } \\
\text { keyboard or electric } \\
\text { guitar }\end{array}$ & $\begin{array}{l}\text { Hypersensitive to loud } \\
\text { noises or boisterous } \\
\text { environments, seeks out } \\
\text { quieter areas }\end{array}$ \\
\hline P3 & Mid 20s & Non-verbal skills & No preference & $\begin{array}{c}\text { Often displayed a sense } \\
\text { of detachment, } \\
\text { withdrawal and non- } \\
\text { participation }\end{array}$ \\
\hline $\mathrm{P} 4$ & Late $20 \mathrm{~s}$ & $\begin{array}{c}\text { Non-verbal skills, uses vocal and } \\
\text { facial expression, gesturing and } \\
\text { pictorial methods }\end{array}$ & $\begin{array}{c}\text { Preference for } \\
\text { percussion and stringed } \\
\text { instruments }\end{array}$ & $\begin{array}{c}\text { Known to have an interest } \\
\text { in computers }\end{array}$ \\
\hline P5 & Mid 20s & $\begin{array}{c}\text { Non-verbal skills, uses vocal } \\
\text { expression }\end{array}$ & Use of voice & $\begin{array}{l}\text { Emotional expression } \\
\text { through use of } \\
\text { microphone }\end{array}$ \\
\hline P6 & Early 20 s & Functional language skills & $\begin{array}{l}\text { Use of voice and } \\
\text { keyboards }\end{array}$ & $\begin{array}{l}\text { Spontaneous verbal } \\
\text { communication and } \\
\text { improvisation through } \\
\text { keyboard and singing }\end{array}$ \\
\hline G1 & $\begin{array}{l}\text { Both in } \\
\text { Mid 20s }\end{array}$ & $\begin{array}{l}\text { One with non-verbal skills and } \\
\text { one with functional language } \\
\text { skills }\end{array}$ & $\begin{array}{l}\text { One prefers percussion } \\
\text { and strumming guitar, } \\
\text { the other singing and } \\
\text { playing percussion }\end{array}$ & $\begin{array}{l}\text { Childhood friends, both } \\
\text { quite fluent with the use } \\
\text { of computers }\end{array}$ \\
\hline
\end{tabular}

All participants, with the exception of one newly referred client, had previously taken part in therapeutic music sessions within TouchBase. All of the participants' parents or guardians were contacted directly by the music tutor several weeks prior to the study for approval, to allow any changes in participants' routines to be planned for, and for responses to be submitted. One of the males and one female worked together as a group $(\mathrm{G} 1)$, while the other six participants took part in one-to-one sessions with the music tutor (P1-P6). All participants had been diagnosed with ASC. Parents or guardians provided informed consent for their children to be involved in the study. All participants were between the ages of 18 and 28 years. 


\subsection{Materials}

The music sessions took place in a large room and had the following musical instruments available: acoustic and electric guitars; microphones; an assortment of acoustic and electronic percussion; a harp and electronic keyboard (Figure 3).

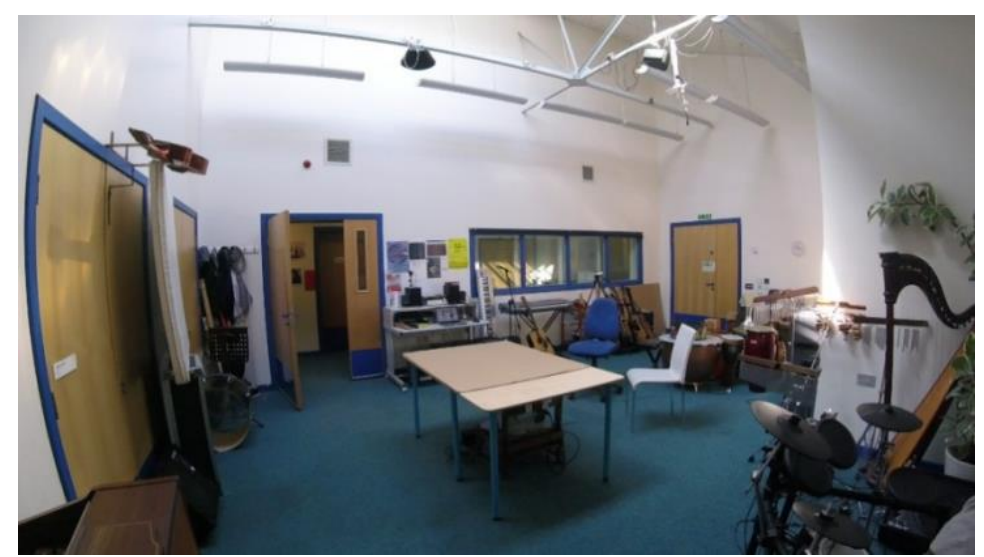

Figure 3: TouchBase music room.

All instruments could be height adjusted to suit each participant either sitting or standing. Chairs were available for both participants and the tutor. A variety of beaters and drumsticks were also available. Two video cameras were installed to record the sessions: one mounted on top of a cymbal stand in the corner of the room; another placed on a small stand near the entrance to the room. The CymaSense prototype was run on an Apple MacBook laptop [95] connected to a Focusrite Scarlett 2i2 [96] audio interface, placed at the side of the room. The laptop also provided access to the user interface for music tutor and participants, allowing customisation for each user, including control of colour schemes (see Figure 4).

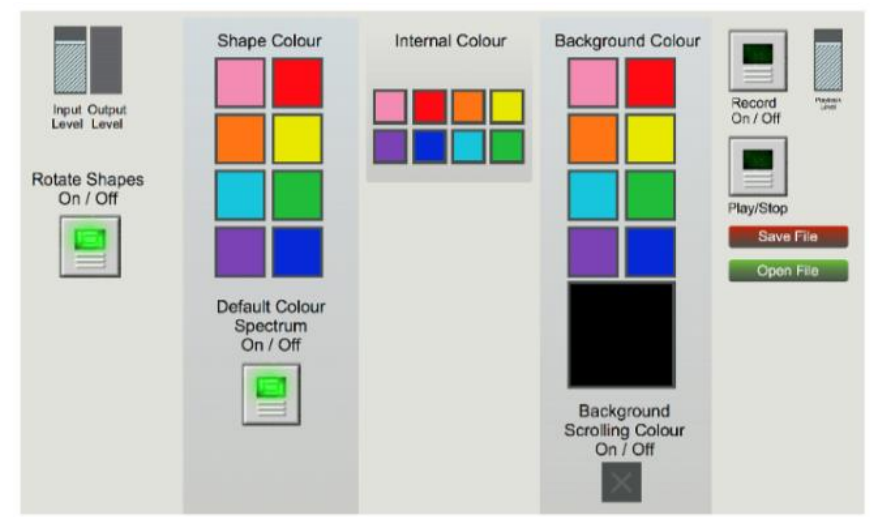

Figure 3: CymaSense Interface

A default colour scheme was created for CymaSense based on associating RGB values with the 12 notes of the musical scale beginning with note of $\mathrm{C} 4$ (see Figure 5).

The prototype was used in three distinct scenarios, detailed in Table 2.

Table 2: Use of the prototype within the study sessions

\begin{tabular}{|l|l|}
\hline Prototype use & Description \\
\hline One Microphone & 1 microphone processes room audio, 1 set of projected shapes \\
\hline Two Microphones & 2 microphones process 2 audio inputs, 2 sets of projected shapes \\
\hline Interactive Table & $\begin{array}{l}\text { CymaSense interactive surface creates sound and projects shapes beneath its } \\
\text { surface when played }\end{array}$ \\
\hline
\end{tabular}




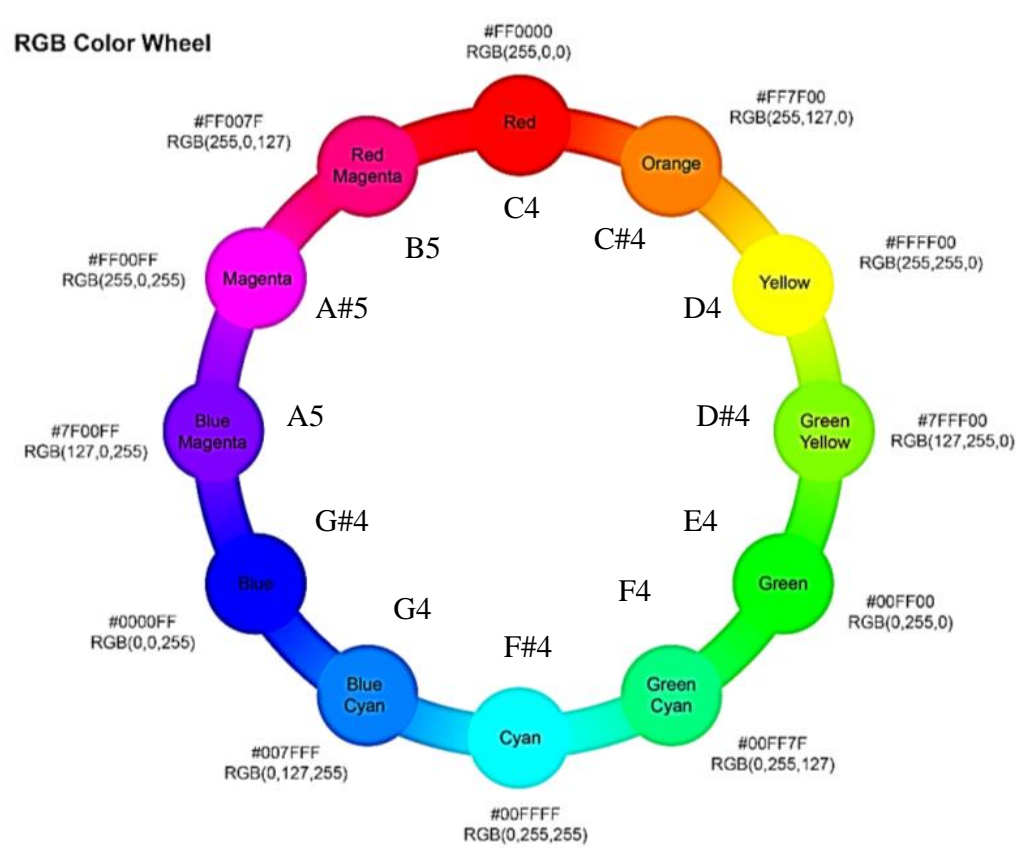

Figure 4: Colour wheel indicating the RGB values associated with musical notes, used as the default colour scheme used in CymaSense (modified colour wheel, original source Van De Vall, 2013)

The three different configurations of the prototype were tailored to the needs of each participant, which were monitored prior to, and during, the intervention sessions (see Table 3). In scenario 1, a microphone on a stand was used to capture all sounds that were audible within the room. The microphone was placed near the wall beside the laptop, behind participants and out of their line of sight. This allowed the tutor to use any instrument within the room and minimise changes to the established routine for the participants. A tripod-based projector on one side of the room projected the visual output from the laptop onto a screen of approximately 5 feet in length by 4 feet in height (See Figure 6)[88]. No shapes would be visible until the audio input was sufficiently greater than the ambient room level.

\section{Table 3: Participant Prototype use of CymaSense}

\begin{tabular}{|c|c|}
\hline P1 & $\begin{array}{l}\text { Played interactive table with hands and beaters, rhythmic improvisation with tutor playing } \\
\text { drums or other instruments. }\end{array}$ \\
\hline $\mathrm{P} 2$ & Turn taking on the interactive table, also improvised along with tutor on drums. \\
\hline P3 & Tapping of the interactive table for with hands/fingers. \\
\hline P4 & $\begin{array}{l}\text { Played interactive table, played other percussive instruments, which would be visualised via } \\
\text { the table as well. Changed colour schemes on the user interface. }\end{array}$ \\
\hline P5 & Preference for the 2-user version of CymaSense with a microphone. \\
\hline P6 & $\begin{array}{l}\text { A room microphone visualised keyboard playing and singing; played the interactive table; } \\
\text { vocal interaction with the tutor using the } 2 \text {-user version. }\end{array}$ \\
\hline G1 & $\begin{array}{l}\text { A single microphone for visualisation of room sounds or solo voice; played the interactive table; } \\
\text { one member of the group also took frequent control of changing colour schemes. }\end{array}$ \\
\hline
\end{tabular}




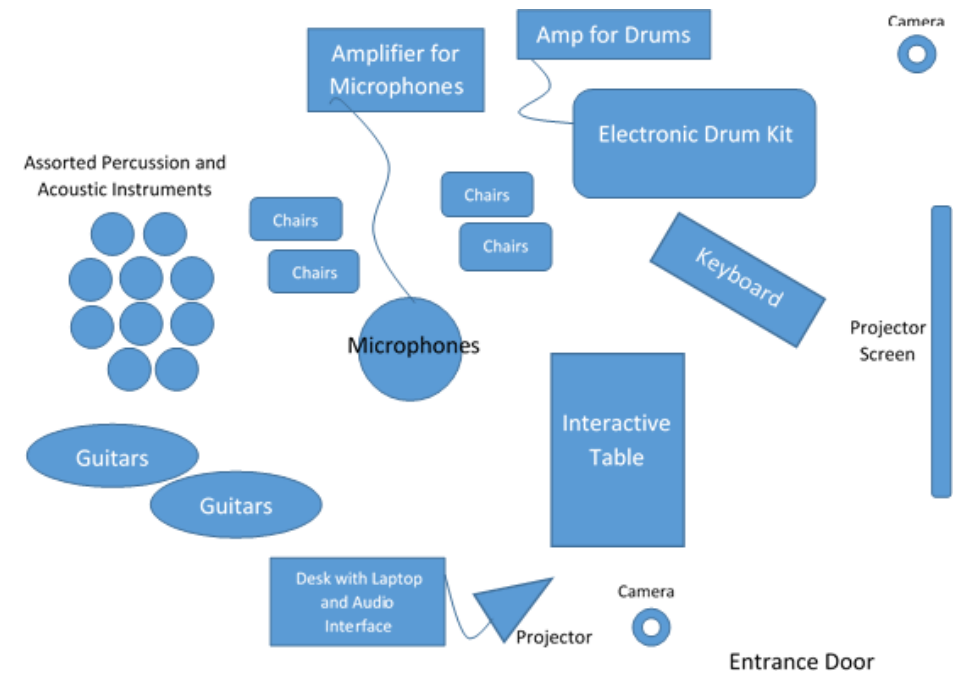

Figure 5: Music room layout

In the second scenario, two microphones captured audio inputs for the 2-user version of the prototype, allowing the tutor and participant to control their own set of shapes through the use of their voice or chosen instrument. The 2-user version was also projected onto the screen with each set of Cymatic shapes positioned side by side (See Figure 7)[89]. In the third scenario, an interactive table was used as an alternative means of using the prototype, presented as a tangible user interface within the room. The extent of the interactivity was restricted to playing the table in a percussive manner with hands or beaters for participants' or the music tutor. Tapping or striking the table activated sounds from an electronic percussive synthesiser in addition to simultaneous projection of the CymaSense output on the underside of the table. No shapes would be visible until sufficient contact with the table surface had been made. This facilitated the needs of those participants who were less capable of eye-hand coordinated activity playing an instrument and looking at the screen - as well as those who were driven by rhythm-based activities [90].

The table design comprised: a 70 $\mathrm{cm}$ x $70 \mathrm{~cm}$ Perspex transparent surface; a contact microphone to pick up audio vibrations; an interface adapter for an iPad [97]; Impaktor, an iPad application that generates percussive synthesised sounds [98]; a small amplifier and loudspeaker; and a projector to visualise the CymaSense output on the underside of the table surface (see Figure 7)[91][25]. Following completion of the sessions, a post-study questionnaire was provided to parents, care workers and the music tutor to gather qualitative data concerning observable changes in the participants' behaviours outside of the sessions (see section 4.5).


Figure 6: Music tutor and an anonymised participant using the CymaSense Interactive table (left), and projected on to a screen (right). 


\subsection{Design}

The 12-week study evaluating the CymaSense intervention was implemented over two phases, the first over eight weeks, followed by a 7-week break, with the second follow-up phase taking place over four weeks (see Figure 8). No contact with participants occurred during the break, following agreement with them regarding only being contacted during the sessions. This also aided in removing any possibility of influencing their communicative behaviours during the second phase.

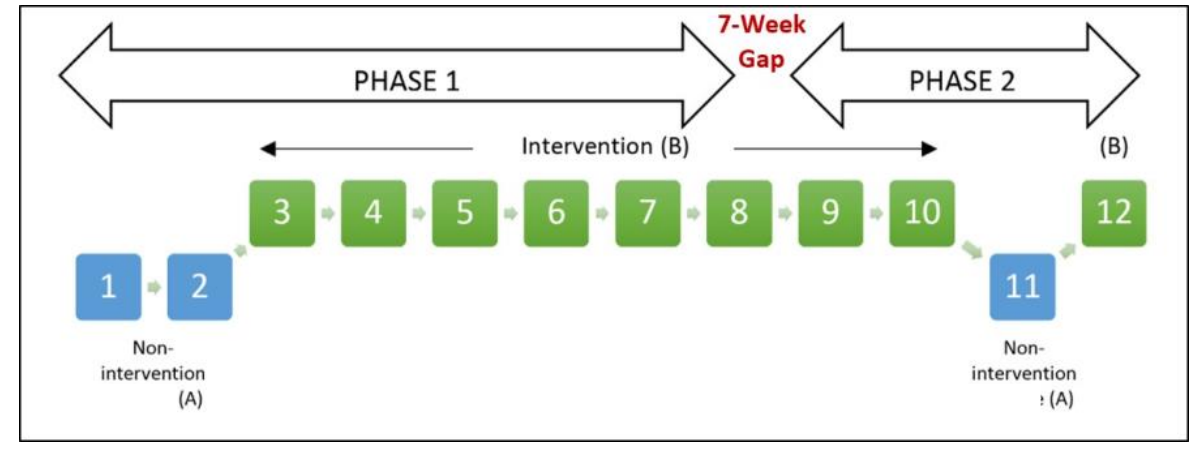

Figure 7: Overview of the 12 week study.

Phase 1. In our study, autistic participants took part in an initial 8-week study (Phase 1), in which CymaSense was used during music sessions. The sessions were video recorded and analysed using quantitative and qualitative methods. Phase 1 followed an $\mathrm{AB}$ design, whereby A represents the preintervention stage ( 2 weeks without CymaSense), followed by B (6 weeks with CymaSense), during which the intervention was implemented. This $\mathrm{AB}$ protocol was also used by Yang and colleagues to examine social behaviour in 7-to-9 year old children with ASC [99], and in studies researching the effects of social stories on autistic children [100][101].

Phase 2. After a 7-week gap, 4 weeks of follow-up sessions (Phase 2) were run according to a BAB reversal design consisting of three stages: (B) a 2-week continuation of the intervention from the Phase 1 study; (A) a reintroduction of the pre-intervention stage for one week; and finally the intervention (B) for one final session.

The Checklist of Communicative Responses/Acts Score Sheet (CRASS), proposed by Edgerton [76] to evaluate autistic participants' responses to improvisational music therapy approaches, was used to analyse musical and non-musical communicative responses via video behaviour analysis. Divided into two sections: musical CRASS data deals with communicative responses initiated by the tutor, and actions initiated by the participant that demonstrate an element of independence (see Table 4); non-musical CRASS data similarly details responses and actions including eye contact, verbal, vocal and gestural communication. The number of occurrences of musical and non-musical communicative responses were totalled for each session and were used to test Hypothesis (1).

A total of 88.5 hours of video were analysed (two cameras recorded six weekly 30 -minute sessions plus one 60-minute group session over 12 weeks - minus absences). Time sampling was not used within the study due to the diverse range of participant skills and abilities, and would be suited with a more predictable series of events and structures. The study was interested in capturing the experience as it happened at the time in relation to what the tutor was doing, rather than when it fell within the session, because each session was customised on the day in real time, based on the needs of each participant. In addition to the video material, questionnaires were used as a means to gather qualitative data (Appendix A). Parents and carers of the participants, as well as the music tutor, were asked to provide information on participants' behaviours before and after the sessions, as well as any observable changes in behaviour at home. This post-study questionnaire provided qualitative data concerning observable changes in the participants' behaviours outside of the sessions. Based on Edgerton's behaviour change survey [76], the questions were grouped into three categories matching Edgerton's categorical design: questions 1 to 6 regarding communicative behaviours; questions 7 to 14 regarding social/emotional behaviours; and 
questions 15 to 17 regarding musical behaviours. This data was used to test Hypothesis (2).

Table 4: Definition of CRASS Behaviours

\begin{tabular}{|c|c|c|}
\hline \multirow[b]{2}{*}{ Behaviour } & \multicolumn{2}{|c|}{ Definition } \\
\hline & Musical & Non-Musical \\
\hline Verbal - responses and acts & $\begin{array}{l}\text { Words or phrases created by the } \\
\text { client during musical play }\end{array}$ & $\begin{array}{l}\text { Words or phrases created by the } \\
\text { client external to musical play }\end{array}$ \\
\hline Vocal - responses and acts & $\begin{array}{l}\text { Vocalisations created and phrases } \\
\text { created by the client during } \\
\text { musical play }\end{array}$ & $\begin{array}{l}\text { Vocalisations created and } \\
\text { phrases created by the client } \\
\text { external to musical play }\end{array}$ \\
\hline Gestural - responses and acts & $\begin{array}{l}\text { Movement of part of the body, } \\
\text { phrases created by the client } \\
\text { signalling an idea or } \mathrm{m}\end{array}$ & $\begin{array}{l}\text { Movement of part of the body, } \\
\text { phrases created by the client } \\
\text { signalling an idea or meaning }\end{array}$ \\
\hline Eye Contact & $\begin{array}{l}\text { Non-verbal communication via } \\
\text { eyes of client and tutor }\end{array}$ & $\begin{array}{l}\text { Non-verbal communication via } \\
\text { eyes of client and tutor }\end{array}$ \\
\hline Initiated by the tutor & Musical & Non-Musical \\
\hline Matches a beat & $\begin{array}{l}\text { Client imitates tutor's rhythm } \\
\text { using their body or an instrument } \\
\text { for a minimum of } 1 \text { measure }\end{array}$ & $\mathrm{n} / \mathrm{a}$ \\
\hline $\begin{array}{l}\text { Simultaneously imitates a } \\
\text { melodic motif }\end{array}$ & $\begin{array}{l}\text { Client imitates tutor's melodic } \\
\text { phrase by use of voice or } \\
\text { instrument }\end{array}$ & $\mathrm{n} / \mathrm{a}$ \\
\hline $\begin{array}{l}\text { Simultaneously imitates the } \\
\text { rhythm of a melodic motif }\end{array}$ & $\begin{array}{l}\text { Client imitates tutor's melodic } \\
\text { rhythm by using body, voice or } \\
\text { instrument }\end{array}$ & $\mathrm{n} / \mathrm{a}$ \\
\hline $\begin{array}{l}\text { Participates in a rhythmic } \\
\text { give and take }\end{array}$ & $\begin{array}{l}\text { Client and tutor play a percussive } \\
\text { exchange for a minimum of } 2 \\
\text { phrases }\end{array}$ & $\mathrm{n} / \mathrm{a}$ \\
\hline Initiated by the Client & Musical & Non-Musical \\
\hline Creates a rhythmic pattern & $\begin{array}{l}\text { Client initiates percussive pattern } \\
\text { using body, instrument or voice }\end{array}$ & $\mathrm{n} / \mathrm{a}$ \\
\hline $\begin{array}{l}\text { Develops a melodic give and } \\
\text { take }\end{array}$ & $\begin{array}{l}\text { Client initiates and leads melodic } \\
\text { exchange with tutor }\end{array}$ & $\mathrm{n} / \mathrm{a}$ \\
\hline $\begin{array}{l}\text { Spontaneously creates a new } \\
\text { melodic phrase }\end{array}$ & $\begin{array}{l}\text { Client improvises melody with } \\
\text { voice or instrument }\end{array}$ & $\mathrm{n} / \mathrm{a}$ \\
\hline Other & $\begin{array}{l}\text { Any undefined percussive or } \\
\text { melodic musical behaviour }\end{array}$ & $\begin{array}{l}\text { Any undefined communicative } \\
\text { non-musical behaviour }\end{array}$ \\
\hline
\end{tabular}

\subsection{Procedure}

Each participant was scheduled for a 30-minute session per week, with the exception of the group (G1) who were scheduled for a 60-minute session each week. Within TouchBase, regular one-to-one weekly sessions are 30 minutes long whilst group sessions are normally 60 minutes. Due to illnesses, unforeseen circumstances and external commitments, not all the participants were able to attend each of the sessions. On average, the attendance was $83 \%$. During the non-intervention stage (A) the music tutor used a number of improvisational musical techniques. For example, the tutor would sit face-to-face with a 
participant whilst playing guitar and singing as an introduction to the session to establish eye-contact, and encourage the participant to strum the guitar. If the participant was uncomfortable with close physical proximity, the tutor would back off slightly and continue to gauge their mood through their reactions to playing of the instrument. At other times he would sit side-by-side, or across from a participant, playing single notes on the keyboard, or tapping on drums, to encourage participants to do the same to encourage give-and-take or imitation activities. Two-way activities would be established and grow into more complex musical conversations to develop and encourage the participant to explore and express themselves through play. Similarly, the interactive table was used for this purpose. If a participant was comfortable initiating independent melody or rhythm, the tutor would play the drums or vocalise on a microphone to accompany them and encourage further improvisation. The techniques were aimed at establishing contact with and facilitating responses from the participants as well as developing their musical and rhythmical abilities. The music tutor played and provided each participant with the opportunity to do the same. Similar to Lazar and colleagues [73], the tutor made every attempt to be sensitive to the desires, goals, and emotions of the participants, by providing support and minimising the imposition of meanings, ideas, or preferences onto their interactions.

Adopting a comparable approach to Frauenberger and colleagues [72] prior to the intervention stage (B), a discussion between the music tutor (as Play Partner) and the researcher (as Active Observer) took place, allowing a review of each of the participant's needs. The discussion was formalised through a short semistructured interview and is discussed in more detail below.

Analogous to Ringland [21] and Cibrian [102], the participant's natural body interactions with the tutor from a musical perspective were taken into account. For example, P1 preferred a sitting position leaning slightly forward for rhythmic play, while P5 liked to lean back whilst sitting with a microphone to make use of his voice more effectively.

People with ASC can exhibit considerable distress when exposed to unfamiliar situations, changes in routine, or changes in environment [1]. Therefore, a phased approach for the introduction of CymaSense was chosen to minimise the effects of stress on each participant. Designed to identify and agree upon each participant's communication and musical abilities, a short interview with the music tutor confirmed the most appropriate way to customise and introduce the intervention. The intervention phase (B) was introduced gradually within a session, once each participant was identified as being comfortable, which would generally take around five minutes. The intervention involved projecting the visualisation of the sound produced by the instruments chosen by participants and music tutor, either on a screen, or using an interactive table (see Figure 5). The laptop interface (Figure 7) was introduced to the majority of participants by the music tutor in week 5 , with the exception of one (P4) who showed interest in exploring the interface on the introduction of the intervention in week 3, by using the mouse to select and change colours. In general, during weeks 3 and 4, the music tutor introduced CymaSense using the default colour scheme (Figure 8).

In week 5, the music tutor encouraged physically capable participants to use the mouse and select different colours, and then would indicate the visible changes by pointing towards the screen or table to demonstrate the results to participants. For participants who remained in their chairs or would not show interest in coming over to the laptop, the music tutor would initially encourage them to indicate approval or disapproval through gestural and verbal means for different colour schemes. For those participants who did not show interest in engaging, the default colour scheme was selected.

The TouchBase music room was designed for use by service users with a variety of disabilities including people on the autism spectrum who are hypersensitive to light. The music tutor had the ability to alter the lighting levels in the music room over the session using adjustable roof blinds to allow control of available light (ranging from complete darkness to daylight) and adjustable windows to control the amount of air entering the space. This allowed the participants to become more comfortable, aware and engaged with the audio-visual interaction. During the intervention phase, the music tutor continued to attempt to respond to each participant's individual needs, based on the amount of gestural, verbal, vocal and musical responses and acts within each session.

The sessions were customised for each participant, however, a general set of structured activities were as follows: (1) Directed activity - the tutor began sessions with an introductory welcome and interaction 
with a chime bar. He would continue with personalised interaction with each participant's chosen instruments and/or voice. At the end of the sessions, conclusory activities included simple breathing and stretching exercises (2) Free activity - the music tutor would identify favoured instruments for each participant and encourage them to initiate interaction during the sessions. Independent play was also encouraged with the tutor being on-hand whenever the participant required assistance or encouragement. The non-intervention session in week 11 was a continuation of the same routines, but without the CymaSense application.

The music tutor was alone in the room with the participants with the exception of a few unanticipated interruptions, from other members of staff, and on occasion when the researcher's help was required with the prototype, which occurred on average once a week. The researcher was sat in the control room next door to the music room for technical support when required throughout the sessions but was not monitoring or reviewing the activities as they took place. At the end of the sessions the tutor would have informal chats with the participants who had verbal skills as they were preparing to leave, concerning what they thought of the CymaSense application. Informal feedback was not recorded for analysis.

The information presented here describes the procedure for phases 1 and 2 of the study, leading to the interviews in phase 3, which will be presented within the method for follow-up interviews (section 5).

\subsection{Phase 1 Results}

The Wilcoxon Matched-Pairs Signed-Ranks Test [103] is commonly used when dealing with nonnormally distributed non-parametric data. Both median and mean can be used to calculate Wilcoxon Signed Ranks Tests. Similarly, to the Edgerton [76] study, the session means formed the basis for a series of comparative tests between sessions. The present study is based on Edgerton's method, which calculated group mean CRASS scores for each weekly session from 10 participants on non-parametric data. Participant data is presented in tabular format in table 5 .

Table 5. Musical (left) and non-musical (right) CRASS data for Phases 1 and 2. Dashes represent absences.

\begin{tabular}{|c|c|c|c|c|c|c|c|}
\hline \multicolumn{7}{|c|}{ Participant CRASS Data } \\
\hline & P1 & P2 & P3 & P4 & P5 & P6 & G1 \\
\hline Week 1 & $22 / 19$ & $20 / 14$ & $7 / 13$ & $13 / 10$ & $11 / 4$ & $17 / 14$ & $21 / 16$ \\
\hline Week 2 & $16 / 13$ & - & $4 / 16$ & $17 / 8$ & $14 / 6$ & $23 / 11$ & $13 / 17$ \\
\hline Week 3 & $42 / 37$ & $15 / 9$ & - & $27 / 22$ & - & $32 / 20$ & $32 / 34$ \\
\hline Week 4 & - & $25 / 19$ & - & $19 / 23$ & $34 / 17$ & - & $29 / 35$ \\
\hline Week 5 & $40 / 41$ & $36 / 39$ & $11 / 24$ & $37 / 41$ & $49 / 20$ & $35 / 45$ & $46 / 36$ \\
\hline Week 6 & $46 / 52$ & - & - & $58 / 95$ & $63 / 12$ & $37 / 46$ & $76 / 87$ \\
\hline Week 7 & $43 / 66$ & $50 / 44$ & $24 / 51$ & $34 / 117$ & $58 / 26$ & $55 / 71$ & $75 / 101$ \\
\hline Week 8 & $42 / 51$ & $47 / 85$ & $1 / 34$ & $54 / 182$ & $73 / 68$ & $62 / 84$ & $90 / 133$ \\
\hline \multicolumn{7}{|c|}{$7-$ Week Break between Phase 1 and Phase 2 } \\
\hline Week 9 & $47 / 50$ & $50 / 83$ & $1 / 42$ & $49 / 179$ & $70 / 59$ & - & - \\
\hline Week 10 & $49 / 60$ & $46 / 82$ & $25 / 45$ & $55 / 192$ & - & $58 / 82$ & $86 / 125$ \\
\hline Week 11 & $18 / 35$ & $23 / 40$ & - & $37 / 145$ & $26 / 28$ & $38 / 51$ & $46 / 92$ \\
\hline Week 12 & - & $47 / 77$ & - & $56 / 190$ & $71 / 63$ & $61 / 83$ & $82 / 129$ \\
\hline
\end{tabular}

Individual participant data is presented in a combined line graph in figure 9, while line graphs for individual participants P1 to P6, and the group G1, are available in Appendix B. 


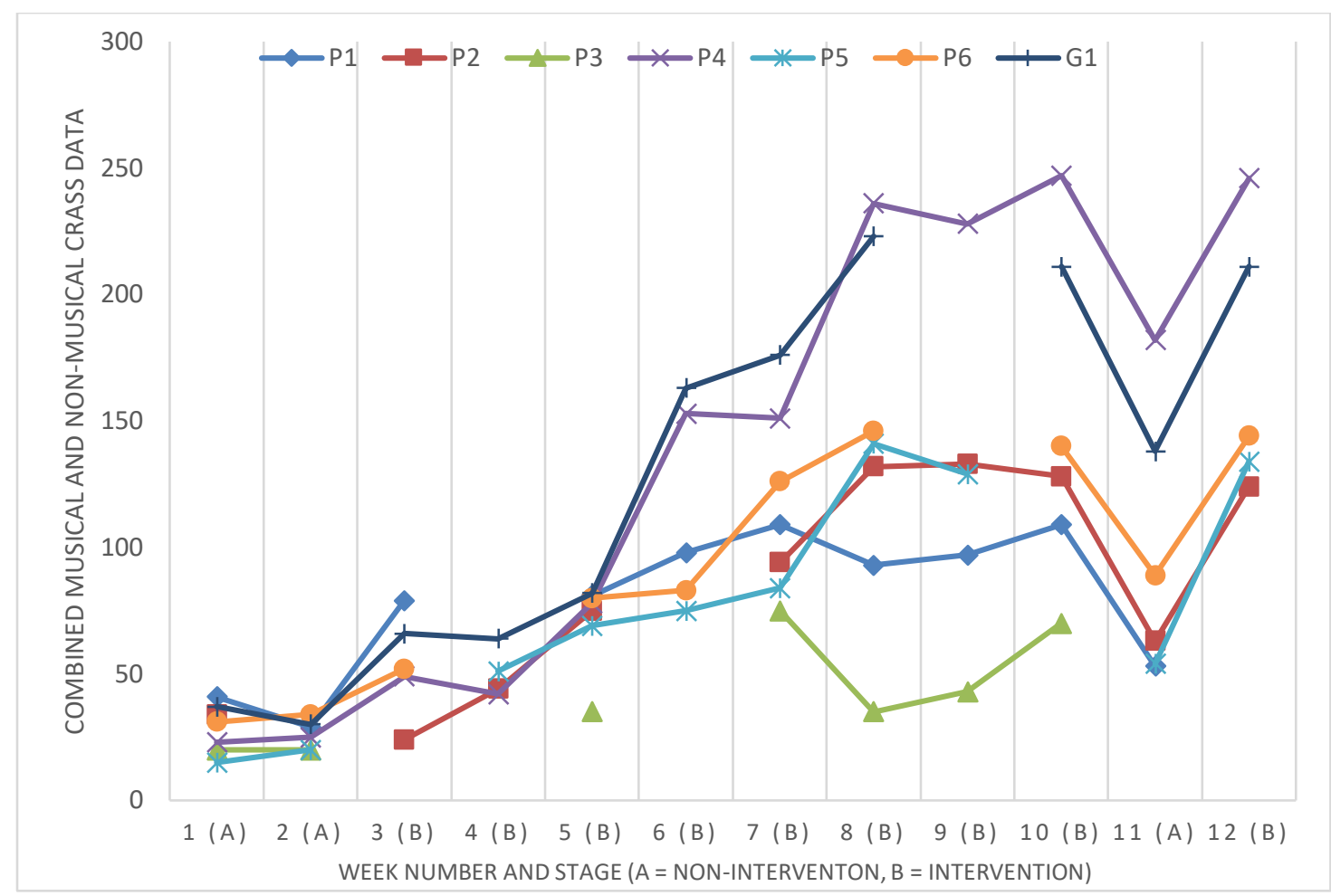

Figure 8: Combined musical and non-musical CRASS scores over weeks 1 to 12 for individual participants (P1 to P6) and group (G1).

The means for musical, non-musical and combined communicative acts and responses (CRASS) for all participants is shown in Figure 10. To evaluate the six individuals and one group of two (G1), it was decided to analyse the data in two distinct ways: (i) by including the group in the analysis and (ii) by excluding the group (see Table 6). All participants' last session scores were greater than their first session scores indicating a positive level of change over the eight sessions in Phase 1. The combined musical and non-musical scores ranged from 55 to 213 points on a scale of 0 to 250 , with a mean of 75.7 with G1, and a mean of 69.8 without G1 included. Musical scores ranged from 23 to 77 including G1 data, 23 to 62 without, with a mean score of 35 including G1 and 32.6 without G1. Non-musical scores ranged

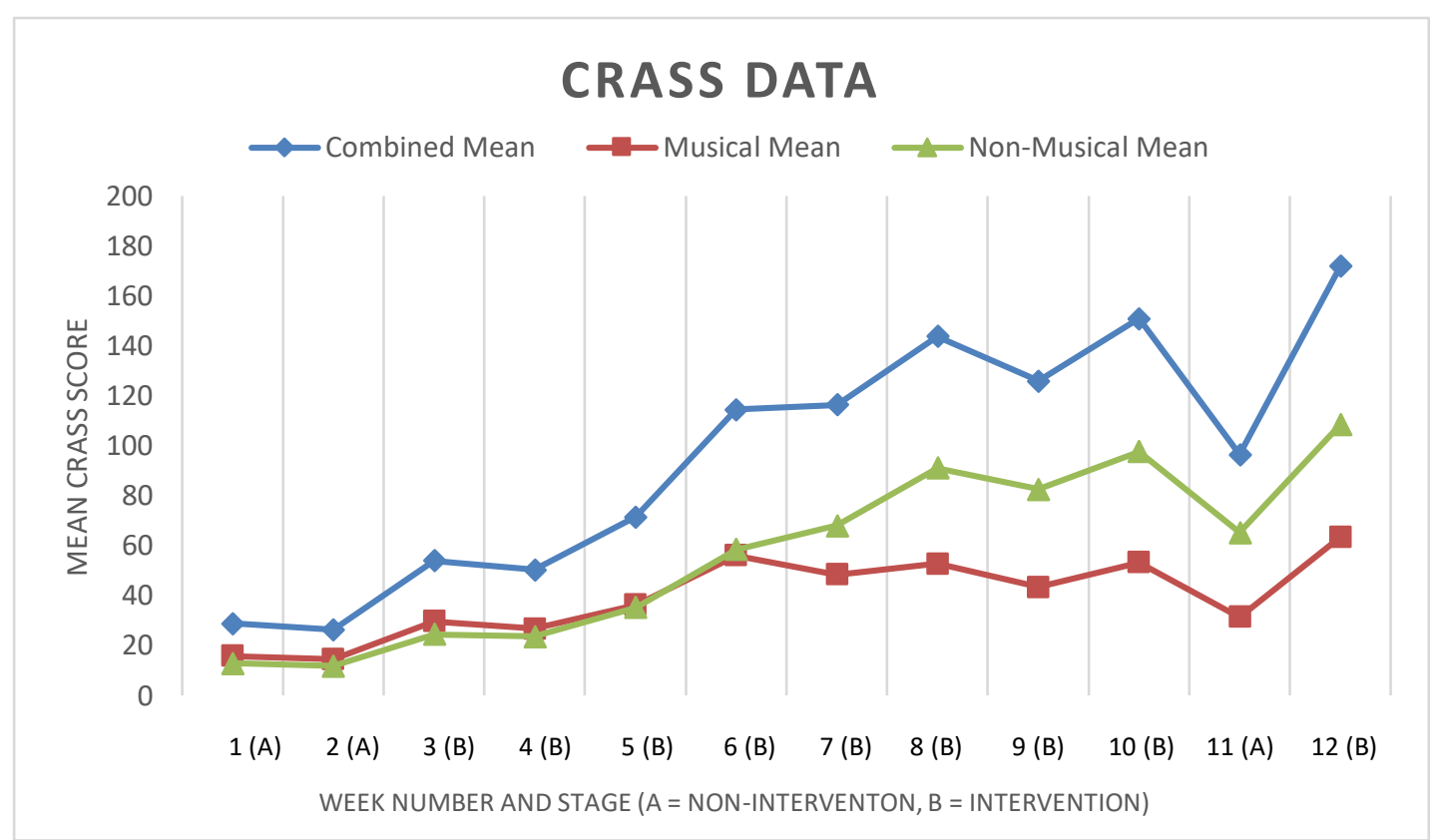

Figure 9: One-to-one and group mean CRASS scores over weeks 1 to 12. 
from 38 to 174 points, with a mean of 40.6 with G1 data included and 37.2 without. An overall increase was noted, however, reduction in scores in sessions 2 and 4 are notable and could be explained by absences skewing the data. This is discussed further in Section 4.7.

The mean scores were compared between the following weeks: (a) the first and last sessions of the trial (weeks 1 and 8); (b) the first and last sessions of the intervention stage (weeks 3 and 8); (c) the third and last sessions of the intervention stage (weeks 5 and 8) - this was to test the effect of resistance to change autistic people often display regarding ritualistic behaviour [104]. It is assumed that by the third intervention week, resistance to change is minimal; (d) sessions two and three, designed to be the last non-intervention and first intervention session; (e) the last non-intervention and first intervention session for all participants. However, absences led to missing data for five of the participants (See Table 5). For all of the above, tests were conducted for the combined musical and non-musical data, musical data only, and non-musical data only (See Table 6).

Table 6. Wilcoxon Matched-Pairs Signed Ranks Tests overview (one-tailed) for Weeks 1 to 8. Results in bold denote a significant difference ( $\mathrm{M}=$ Musical, $\mathrm{NM}=$ Non-Musical).

\begin{tabular}{|l|l|l|l|l|l|l|}
\hline & $\begin{array}{c}\text { Analysis } \\
\text { Type (incl } \\
\text { Texcl } \\
\text { Troup) }\end{array}$ & \multicolumn{1}{|c|}{ Weeks Compared } & $\begin{array}{c}\text { Sample Size } \\
\text { (No. of } \\
\text { compared } \\
\text { data sets) }\end{array}$ & $\begin{array}{c}\text { Combined } \\
\text { M and } \\
\text { NM p-value }\end{array}$ & $\begin{array}{c}\text { M Only } \\
\text { p-value }\end{array}$ & $\begin{array}{c}\text { NMOnly } \\
\text { p-value }\end{array}$ \\
\hline a(i) & Included & 1 and 8 & $7 \times 7$ & $\mathbf{. 0 0 9}$ & $\mathbf{. 0 1 4}$ & $\mathbf{. 0 0 9}$ \\
a(ii) & Excluded & 1 and 8 & $6 \times 6$ & $\mathbf{. 0 1 4}$ & $\mathbf{. 0 2 3}$ & $\mathbf{. 0 1 4}$ \\
b(i) & Included & 3 and 8 & $5 \times 7$ & $\mathbf{. 0 2 2}$ & $\mathbf{. 0 3 4}$ & $\mathbf{. 0 2 2}$ \\
b(ii) & Excluded & 3 and 8 & $4 \times 6$ & $\mathbf{. 0 3 4}$ & .055 & $\mathbf{. 0 3 4}$ \\
c(i) & Included & 5 and 8 & $7 \times 7$ & $\mathbf{. 0 1 4}$ & $\mathbf{. 0 2 2}$ & $\mathbf{. 0 0 9}$ \\
c(ii) & Excluded & 5 and 8 & $6 \times 6$ & $\mathbf{. 0 2 2}$ & $\mathbf{. 0 3 8}$ & $\mathbf{. 0 1 4}$ \\
d(i) & Included & 2 and 3 & $6 \times 5$ & $\mathbf{. 0 3 4}$ & $\mathbf{. 0 3 4}$ & $\mathbf{. 0 3 4}$ \\
d(ii) & Excluded & 2 and 3 & $5 \times 4$ & .055 & .055 & .055 \\
e(i) & Included & Dependent on absence & $7 \times 7$ & $\mathbf{. 0 1 4}$ & $\mathbf{. 0 1 4}$ & $\mathbf{. 0 1 4}$ \\
e(ii) & Excluded & (see table 5) & 6 x 6 & $\mathbf{. 0 2 3}$ & $\mathbf{. 0 2 3}$ & $\mathbf{. 0 2 3}$ \\
\hline
\end{tabular}

A significant difference was observed between first and last session scores for all conditions a(i) and a(ii). The difference between the first and last sessions with intervention were significant for all conditions except $b$ (ii) for musical scores only, $Z=-1.6 ; p=0.055$ (one-tailed), which showed no significant change. To test the introduction of the intervention session for all participants, barring absences, sessions test c(i) and c(ii), demonstrate a significant change for all musical, non-musical and combined conditions. The increase between Sessions two and three d(i) showed only significant differences for one-to-one sessions only at the $\mathrm{p}=.034$ level (one-tailed, $\mathrm{Z}=-1.8$ ). However, the followup test, e(i) and e(ii) comparing all last non-intervention sessions with first interventions sessions, indicates significant levels for all conditions.

\subsection{Behaviour change questionnaire}

A Behaviour Change Questionnaire was completed by four parents, four care workers and the music tutor. Of the 20 questionnaires distributed, 16 were returned ( $80 \%$ return rate). The questionnaire consisted of a series of 7 point Likert scale questions (Appendix A), where a value of: 1 represented the negative end of the scale, for example, the participant responded to you verbally much less since the first session; 4 represented the central position, for example, the participant responded to you verbally the same since the first session; 7 represented the positive end of the scale, for example, the participant responded to you verbally much more since the first session. An additional comments section was available. The means from communicative behaviours and social/emotional behaviours were both at 5.6, with musical behaviours at 5.7, indicating a change from slightly more to somewhat more. The results can be seen in Appendix D.

\subsection{Phase 2 Results}

Figure 9 shows the means for musical, non-musical and combined communicative acts and responses (CRASS) for all participants over all 12 sessions. A reduction in scores between Weeks 8 and 9 could be explained by the 7-week gap between sessions, while the more pronounced reduction in scores in Week 11 corresponds with the intervention withdrawal phase. Table 6 shows non-musical and musical CRASS 
data over the 12 weeks. Participant absences are indicated by the lack of entries in that table, and may have had a limited effect on mean scores. Additionally, although Week 12 scores are notably higher than Week 11's, absences may have affected the overall score. This will be discussed further in Section 4.7.

The analysis of the CRASS data in Phase 2 was undertaken in the same way as Phase 1 . The Wilcoxon Matched-Pairs Signed Ranks Test was used to determine whether the differences observed between weekly sessions were significant (see Table 7). The mean scores were compared between the following weeks: (f) the last session of the Phase 1 (Week 8) and the first session of Phase 2 (Week 9) - data was missing here due to participant absences (see Table 5), so the test covered the last intervention of Phase 1 and first intervention of Phase 2 for all present participants regardless of session number. Specifically, for P6 and G1, a comparison between week 8 and week 10 was made here. Means scores were compared for: (g) the reintroduction of the non-intervention stage (Week 11) and the previous intervention session (Week 10). Due to absences again, this was calculated by removing P3's score, as week 10 was their last attended session, and using P5's last intervention score (Week 9) to compare intervention with the pre-intervention score. (h) Means scores were compared for the last session of the intervention stage (Week 12) and the previous non-intervention session (Week 11) - again, absences meant that the last non-intervention and final intervention of Phase 2 did not include P1 or P3's scores. All of the above, tests were conducted for the combined musical and non-musical data, musical data only, and non-musical data only. Similarly to Phase 1, it was decided to analyse the data in two ways: (i) by including the group in the analysis and (ii) by excluding it.

Table 7. Wilcoxon Matched-Pairs Signed Ranks Tests overview (one-tailed) for Weeks 9 to 12. Results in bold denote a significant difference ( $M=$ Musical, $N M=$ Non-Musical).

\begin{tabular}{|l|l|l|l|l|l|l|}
\hline & $\begin{array}{c}\text { Analysis } \\
\text { Type (incl / } \\
\text { Test }\end{array}$ & $\begin{array}{c}\text { Weeks } \\
\text { Compared }\end{array}$ & $\begin{array}{c}\text { Sample Size } \\
\text { (No. of } \\
\text { compared } \\
\text { data sets) }\end{array}$ & $\begin{array}{c}\text { Combined M } \\
\text { andNM p- } \\
\text { value }\end{array}$ & $\begin{array}{c}\text { M Only } \\
\text { p-value }\end{array}$ & $\begin{array}{c}\text { NM Only } \\
\text { p-value }\end{array}$ \\
\hline f(i) & Included & 8 and 9 & $7 \times 7$ & 0.07 & 0.23 & 0.07 \\
f(ii) & Excluded & 8 and 9 & $6 \times 6$ & 0.12 & 0.34 & 0.12 \\
g(i) & Included & 10 and 11 & $6 \times 6$ & $\mathbf{0 . 0 1}$ & $\mathbf{0 . 0 1}$ & $\mathbf{0 . 0 1}$ \\
g(ii) & Excluded & 10 and 11 & $5 \times 5$ & $\mathbf{0 . 0 2}$ & $\mathbf{0 . 0 2}$ & $\mathbf{0 . 0 2}$ \\
h(i) & Included & 11 and 12 & $5 \times 5$ & $\mathbf{0 . 0 2}$ & $\mathbf{0 . 0 2}$ & $\mathbf{0 . 0 2}$ \\
h(ii) & Excluded & 11 and 12 & $4 \times 4$ & $\mathbf{0 . 0 3}$ & $\mathbf{0 . 0 3}$ & $\mathbf{0 . 0 3}$ \\
\hline
\end{tabular}

\subsection{Discussion}

The results of the study indicate that the combination of improvisational music sessions and use of CymaSense can improve communicative behaviours for some people with ASC. These results support other music therapy related research [41], studies with TUIs [20], and with natural user interfaces (NUI) [21], with respect to enhancing communication for people with ASC. Other music-based interventions including BendableSound [22], MEDIATE [31], and SensoryPaint [21], are based on haptic feedback, gestural interaction, and focus on body awareness. These interventions use sound to enhance the awareness and senses of the participant, rather than being assimilated within a more typical improvisational music therapy environment. CymaSense differs from these systems as it can be used to visualise any acoustic and electronic musical input, including existing accessible MIDI controlled hardware like Skoog [60] or Launchpad [59].

Sense of agency was not measured within this study, however, has been referenced within related work and alluded to within the present research. The affordances provided by BendableSound relate to gestural tapping, dragging, ripping and pinching, which play associated preset animations and allow control of MIDI triggered sounds [22]. Facilitating agency is accomplished through a lack of latency of associated audio-visual feedback with participants' body movements, resulting in potential therapeutic benefits regarding attention and motor development. The MEDIATE application responded to participants' movements, touch and sounds they created, and increased the level of complexity dependent on the amount of non-repetitive behaviours displayed by them [31]. Similarly, contingent interaction was achieved through the lack of latency associated with the visual feedback on screen regarding their body movement. Real-time interaction with the visuals allowed participants to control particle animations, resulting in gaining a sense of control and reducing repetitive behaviours. SensoryPaint facilitates sense 
of agency through reflection of users own movements on screen, the provision of colour to reflect the users proximity, as well as allowing them to draw on screen using various textures and colours of differing sizes [21]. This resulted in balancing participants' attention between their own bodies and sensory stimuli, and promoting socialization. CymaSense allows users to select their own colour schemes from the interface, visualise any instrument that they choose to play, or use the interactive table, either as an individual or shared experience. A lack of latency implemented within the application, is again important between tactile, aural and visual senses being perceived at the same time. Visualisations are sensitive to changes in pitch, volume and timbre, mirroring the user's capabilities and nuances, through changes in size and shape, encouraging play and exploration. Results have demonstrated an increase in communicative behaviours, augmenting existing improvisational music therapy techniques, suggesting an increase in sense of agency amongst some participants.

It cannot be said that the same results will occur on other groups of participants with ASC, due to the understandably small population who took part. At present we do not know the extent to which the Cymatic shapes, the colours, or any individual parameter, are responsible for the increases in communicative behaviours, as other alternative geometric shapes have not yet been tested. This study differs through employing a combination of music therapy techniques, NUIs and TUIs. It provided the participants with an additional sense of agency and independence through the ability to experience tactile, auditory and visual feedback, within an improvisational music setting. A surprising dip in P1's score for the final session in Phase 2 was noticed. It was noted that he was suffering from a heavy cold that day and his subsequent energy levels could have affected his poorer than expected performance. Tiredness is a major factor in general with ASC [27], so it might be argued that this would be expected to have a greater effect than neurotypical participants. Similarly, P5 had dental treatment prior to sessions 4 and 5, making him physically tired and less energetic than normal. Participants' absences have already been stated with regard to their emotional health; additionally, the physical health of some participants is likely to have affected their scores and consequently the results of this study. For example, P1 was also known to have arthritis.

One recognised trait of people with ASC is the fear of novelty or change within a situation [48]. In this study there was no negative novelty effect observed. The results show there was no decrease in CRASS scores when the tool was introduced, and that scores typically increased with use. It is notable that there were no significant changes in overall CRASS scores between the last week of Phase 1 and the first week of Phase two of the study, which was an interval of seven weeks. It is not known whether participants had any form of musical interaction at home during this period, as this was not the intention of the study. However, the participants had not attended any other music sessions within Touchbase in that time. This could indicate that their music session routine was not interrupted, regardless of the 7-week break.

The present study has not been compared to one without use of the intervention to establish whether there are similar trends in rising levels of communicative behaviours due to limited resources. The results of the present study may have been influenced by familiarity with the tutor and surroundings, thus increasing participants' levels of comfort and sense of agency. It has been identified in autistic studies, that routine and predictability has an effect on reducing stress and increasing communicative behaviours [105]. Recognition of a level of routine has to be conceded here. However, without a parallel study with no intervention this cannot be verified. Nonetheless, qualitative feedback from the music tutor provides evidence of working with the same participants in previous music sessions, and the effect of CymaSense on their communicative behaviours within the present study. For example, greater improvisation, development of a performative aspect of musical exploration, greater enthusiasm for shared play regarding the interactive table, and for give and take between the tutor and some participants.

One limitation to interpretation of the data relates to the single subject $\mathrm{AB}$ design used in Phase 1 of the study. The experimental design used may not be as strong as one where the intervention is withdrawn and then reintroduced [27]. A withdrawal phase was considered but was advised against by a music therapy expert from another university, as it may have run the risk of distressing participants if a successful intervention was withdrawn. The ABA design is often criticised for possible ethical issues. In some cases, it may be harmful for the participant to return to the non-intervention period at an early stage [28]. Additionally, the practicalities of carrying out this type of study were an important factor that affected its design. It was challenging to secure the participation of a tutor and participants for a long 
duration, which limited the duration of the different stages of the study. The non-intervention (A) phase was thus decided to be a 2-week period, a compromise that enabled the intervention to be run over a longer stretch of time, which was judged preferable for Phase 1. This decision was also based on the music tutor's prior working experience with the majority of the participants, thus potentially minimising the need for a longer adjustment period. However, following discussion with the music tutor and the participants' parents and carers, consideration for a repeat or continuation of the study resulted in the follow-up Phase 2 for further validation. The results indicate an additional BAB reversal design has provided comparative data to further highlight the positive effect of the intervention on overall communicative behavioural scores.

The video data was coded solely by the author. Additionally, the music tutor watched the video recordings on a weekly basis and provided informal verbal feedback to the researcher. However, if the observational data had been evaluated by additional independent observers, and appropriate inter-rater reliability checks completed, the resultant data may have differed to the data presented in this paper.

Due to the prototype nature of CymaSense, the author was required on occasion to provide technical support during a few of the sessions. This may have disrupted the flow of the session somewhat, due to time taken to identify an issue and restart the application, as well as introducing another person into the environment. Wider deployment of CymaSense would require an update to the software and interface, requiring further testing to increase the levels of robustness, to limit any interruptions to participants' and tutors' roles.

It could be argued that when used as an interactive table, CymaSense not only visualises interaction with the table surface itself, but also creates a novel percussive instrument. Janzen and Thaut suggest musicbased developmental training based on motor control impairments and attention deficits should be addressed as key treatment targets for people with ASD [106]. Other studies support the potential benefit of rhythm-mediated interventions using dyadic drum playing providing preliminary evidence strengthening its use in the social domain for people with ASD [107]. Yoo and Kim demonstrated that participants with high functioning autism showed decreased asynchrony when tapping with a partner at adjusted tempi after the rhythm-mediated intervention. The participants also showed a greater engagement in joint action following the intervention. CymaSense could be used to facilitate rhythmbased interventions and create new opportunities for social interaction through a shared space and turn taking, while independent use could also encourage cause-and-effect and a subsequent sense of agency. The size and location of the projected image may have affected the participants' ability to appreciate the cause-and-effect nature of the system. This was noted by the facilitator and the tutor through constant review of sessions and video and subsequent decisions were made.

An alternative participatory design method with autistic users would likely have developed a different application. Subsequently, the user interface may have been more effective had a participatory design approach been developed at an earlier stage. However, it could also be argued that the Cymatic shapes would not have been introduced as an innovative visualisation aesthetic.

Colour may have affected how participants experienced the sessions. The tutor initially used the default colours (black background and spectrum colours for the Cymatic shapes) for a number of sessions to allow familiarity with the tool. Alternative colours were chosen at random by the tutor in future sessions while some participants chose their own colour schemes. None of the participants was diagnosed with visual impairments. However, further studies would be required to determine the effectiveness of the colours chosen and the effect of environmental factors like temperature or noise - for example, the hum of the projector. Similarly, little is known concerning how the animation of the shapes themselves affected each subject. Again, however, participants with functional language provided positive feedback concerning the dynamic movement and colour responses.

\section{METHOD FOR FOLLOW-UP INTERVIEWS}

Following on from section 4, which presented phases 1 and 2 of the study, phase 3 is presented within this section as the subsequent stage. Follow-up interviews were conducted and recorded, following the CymaSense music sessions, three with parents of the participants, and one with the music tutor involved in the study. The broad goal of the interviews was to gather information about the participants' 
behaviours before and after the sessions in which CymaSense was used. The interviews were also designed to outline how participants' use of the application may have been affected by their own auditory and visual preferences. The interview questions assessed how participants' current use of technology reflected on their use of CymaSense. The study aims to provide insights into the success of CymaSense and inform how the application could be further developed for the benefit of improving communication and social interaction for people on the autism spectrum.

\subsection{Participants}

Parents from all eight study participants were invited to participate in the interview via email and faceto-face where possible, as well as the music tutor. Three parents and the music tutor agreed to take part, providing a response rate of $44 \%$. Due to the low response rate, the interview responses are limited in their representation of the study, and subsequent results will be difficult to generalise. Informal conversations with the parents who responded, suggested an initial reluctance to be further involved in a study that may have required additional time and effort on their part. Two mothers, and a mother-andfather couple, were recruited internally from TouchBase following completion of the 12-week study. The music tutor who ran the sessions was also interviewed. All of the participants' parents were contacted directly by the music tutor several weeks before the interviews were conducted for approval. The music tutor was contacted directly by the researcher. After reading a participant information sheet, all parents and the music tutor provided informed consent for their responses to be included in the study. The two autistic participants from the music sessions with verbal skills were not invited to take part in the interviews, as it was considered by the music tutor that they would not be comfortable responding to a series of questions nor able to sustain a conversation.

\subsection{Materials}

A digital audio recorder was used to record the interviews. The CymaSense application was installed for demonstration purposes to allow parents an opportunity to interact with it themselves. The set-up consisted of a small MIDI keyboard for user input; a laptop to run the software; a sound module to generate a variety of electronic sounds; an audio interface to process the sounds; a small loudspeaker for audio output; and a projector for visual projection of the shapes onto the interview room wall (see Figure 11). Interviewees were also provided with a paper copy of the interview questions.

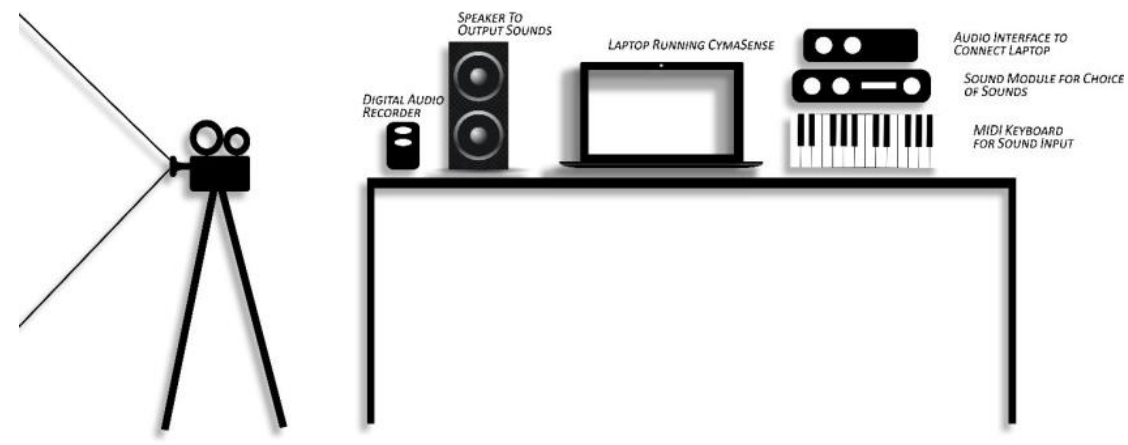

Fig. 11. Setup used to demonstrate CymaSense during interviews. 


\subsection{Design}

A semi-structured face-to-face interview technique was chosen allowing participants the opportunity to elaborate, as additional questions may emerge from the dialogue between interviewer and interviewee. As the symptoms of ASC span multiple domains (e.g., communication and language, social, behavioural), direct answers and anecdotal information could provide insight into the choices made by the study participants. Semi-structured interviews are an effective method used in previous research, as a means to gather qualitative background information including the routines and preferences of each study participant ([108][27]). Cibrian and colleagues used semi-structured interviews to aid in the understanding of behavioural and sensory changes, related to the use of multi-modal interventions within people with ASC [102]. Ringland and colleagues use similar interview methods to ask the parents of participants to provide feedback on their children's use of a multi-sensory intervention, including what they liked and disliked about the SensoryPaint application [21]. Typically, in these studies, parents, caregivers and teachers have provided information regarding individuals' behaviours, and it was hoped that this would provide a greater insight into participants' experience of CymaSense.

The interview questions, 26 in all, were divided into four sections (see Appendix C). The first section included seven questions, which referred to observable behaviour immediately prior to and following the therapy study sessions. Ten questions in Section Two related to the participants' known personal preferences concerning sensory influences. Section Three questions related to participants' general musical preferences. The remaining five questions in Section Four related to the participants' use of technologies and their interaction with CymaSense in particular. Table 8 provides an overview.

Table 8. Overview of Phase 3 interview questions

\begin{tabular}{|l|l|}
\hline Section & Description \\
\hline Pre/Post Therapy & $\begin{array}{l}\text { Questions regarding observable behaviours and emotional stability before } \\
\text { and after sessions }\end{array}$ \\
\hline $\begin{array}{l}\text { Personal Preferences / } \\
\text { Sensory Influences }\end{array}$ & $\begin{array}{l}\text { Questions concerning how issues of hypersensitivity and hyposensitivity } \\
\text { may affect participants }\end{array}$ \\
\hline Musical Preferences & $\begin{array}{l}\text { Questions concerning their listening and playing musical preferences at } \\
\text { home and within sessions }\end{array}$ \\
\hline $\begin{array}{l}\text { Technology and } \\
\text { CymaSense }\end{array}$ & Feedback and opinions on the pros and cons of the CymaSense application \\
\hline
\end{tabular}

Coding was conducted using NVivo [109] where the transcriptions from the interviews based on a qualitative Grounded Theory approach [110]. Codes were allocated to quotations using an open approach where interpretation of quotations suggested appropriate codes, as opposed to pre-defining codes and assigning quotations to them. Following the first pass, which determined a set of 30 codes, a further three passes merged the codes into a condensed set of five, which were checked against the transcripts again for assuredness. An inter-rater reliability check was not necessary due to the small sample size. The results are divided into five sections using the transcript codes as headings for each section, which include: participant behaviour, audio-visual learning, communication, independence and interface (Table 9). Phrases, sentences and short paragraphs were highlighted and assigned to the chosen codes, depending on how exacting or anecdotal interviewees' responses were to the questions. The number of instances of interpreted quotations for each interviewee was noted and the list was ranked according to frequency. 
Table 9. Interview Transcript Codes and Descriptions

\begin{tabular}{|l|l|}
\hline Code & Descriptions \\
\hline $\begin{array}{l}\text { Participant } \\
\text { Behaviour }\end{array}$ & $\begin{array}{l}\text { Participant behaviour is affected by sensory influences, and by familiarity with } \\
\text { people and routine. Behaviour prior to, during, and following the study sessions is } \\
\text { discussed. }\end{array}$ \\
\hline $\begin{array}{l}\text { Audio-Visual } \\
\text { Learning }\end{array}$ & $\begin{array}{l}\text { Observations on how participants' audio-visual aesthetic choices affect the efficacy } \\
\text { of multi-sensory interaction. }\end{array}$ \\
\hline Communication & $\begin{array}{l}\text { Observations on development of participants' communication, from a musical and } \\
\text { non-musical perspective, over the course of the study. }\end{array}$ \\
\hline Independence & $\begin{array}{l}\text { Opinions on the importance of participant control and independence in the music } \\
\text { sessions through use of the CymaSense application. }\end{array}$ \\
\hline Interface & $\begin{array}{l}\text { The playability and accessibility of CymaSense are discussed, and how they affected } \\
\text { creativity. }\end{array}$ \\
\hline
\end{tabular}

\subsection{Procedure}

The four subjects were interviewed individually within a private interview room at the TouchBase centre. In addition, the interviewees offered opinions and comments on previously undiscussed elements related to the study. Some of the questions relating to participants' musical preferences at home were not relevant to the music tutor, and thus were not asked of him. However, the tutor was able to provide opinion on participants' musical preferences within the music sessions. The interviews were expected to last up to an hour and varied in length between 25 and 47 minutes. Interviews were audio recorded, transcribed, and then coded using NVivo [111].

\subsection{Results}

The interviewees commented most on participants' behaviours prior to and post study. They indicated that, in general, participants' anxious behaviours tended to give way to relaxed and stimulated experiences prior to, during, and after the sessions as the study progressed, and for a period of time following the completion of the study. Interviewees identified their children's visually driven learning capabilities, and how they may have assisted in facilitating a stimulating and novel audio-visual experience within the music sessions. Interviewees suggested that the participants' use of CymaSense influenced independent interaction with the application, followed by a sense of control, which facilitated an invitation for the music tutor's participation. The tutor recognised the application's ease of usability and accessibility, through the lack of need for training, and in its ability to be customised easily for each participant. Subsequent increased levels of participant communication associated with the sessions, were identified by the parents. The five derived code descriptions are described below followed by detailed findings from the transcripts (see Table 9).

The interviewees are referred to within the results as PA1, PA2, PA3 and MT, for the purposes of anonymization. A summary of instances from the transcripts, and the interviewee contributions, are described in Table 10. Sections 5.5.1 to 5.5.5 describe each of the codes with instances divided into responses from each of the interviewees for comparison. The majority of the feedback has come from the tutor due to his one-to-one interaction with all of the participants throughout the sessions. 
Table 10. Summary of Code Instances from Transcripts

\begin{tabular}{|l|c|c|c|c|c|c|c|}
\hline Code & Respondents & Instances & \multirow{2}{*}{$\%$} & \multicolumn{3}{|c|}{ Interviewee Contribution (\%) } \\
\cline { 5 - 8 } & & & & PA1 & PA2 & PA3 & MT \\
\hline Participant Behaviour & 4 & 108 & 35 & 24 & 17 & 11 & 48 \\
\hline Interface & 3 & 81 & 27 & 17 & 0 & 19 & 64 \\
\hline Independence & 4 & 51 & 17 & 38 & 5 & 6 & 51 \\
\hline Audio-Visual Learning & 4 & 44 & 14 & 33 & 23 & 24 & 20 \\
\hline Communication & 4 & 20 & 7 & 36 & 5 & 21 & 38 \\
\hline
\end{tabular}

\subsubsection{Participant Behaviour}

Participant Behaviour is the highest ranking code with 108 instances, using words and phrases related to factors that affect the routines and general development of participants, from 'unsettled' and 'withdrawn', to 'excitement', and 'joyful'. Participant behaviour is affected by sensory influences, and by familiarity with people and routine. Behaviour prior to, during, and following the study sessions was discussed. The majority of participants in the CymaSense music sessions had worked previously with the music tutor, with the exception of one new TouchBase service user. Nonetheless, sufficient time had passed for participants to require a period of reacquaintance.

\section{PA1}

PA1 commented that P4's lack of familiarity with the music tutor and the environment affected the routines and levels of comfort - "generally unsettled...nervous about coming to a new situation" (PA1). These factors, combined with varying levels of hypersensitivity and hyposensitivity, resulted in differing levels of emotional stability and subsequent behaviour - "when we're out [P4] has problems".

In addition, hyposensitivity could also cause issues with dexterity - "[they] don't realise when things fall". It could be inferred, however, that the predictability of the situation affects the hypersensitivity of the stimulus "Sounds that come suddenly at a certain pitch,[they'll] scream . . . headphones are a protection measure". Similarly, from a hyposensitivity perspective, it was also pointed out that regardless of "bad fine motor coordination" the same participant "can handle a computer mouse and get on your iPhone with huge fingers without making a mistake".

PA1 noted that P4's behaviour did change once familiarity within the room and sessions took place "When [they] knew what was going on, it sort of coincided with [them] being more confident in [their] environment'. PA1 continued “. . . when [the tutor] comes out and [the tutor's] got the key, [P4] is away like a shot [toward the session]". The interviewee also pointed out P4's enthusiasm after a session - "[P4] was so excited, speaking and repeating, and trying to get the idea over all the way back in the car to the house".

\section{PA2}

Regarding sensitivity, PA2 also mentioned that being touched was an issue - "[P2] doesn't like to be touched...by people, by strangers". Aurally, volume of sound may not be a problem, but rather its predictability - "Although [P1] likes [their] music loud, [they don't] like to hear [other] people's noise". Visual hypersensitivity was also identified - "[P2] likes to be in the dark". However, the interviewee commented on his manual dexterity - 'He's good with his hands'. PA2 also identified a positive response following the sessions - "I come up at 4 o'clock and he's enjoyed the music session".

\section{PA3}

The interviewee indicated that sensory influences could affect participants in a number of ways. Aural hypersensitivity was specified as a common issue - "If it's quite a squeaky high voice, [P1] doesn't like that, [they'll] put [their] fingers in [their] ears". They went on to indicate changes in participant behaviour in the weeks following completion of the sessions - "at the time yes, [P1's] behaviour did change". 


\section{MT}

The music tutor reported that participants tended to be apprehensive before the music sessions began, resulting in a range of anxious behaviours - "[they'd] refrain from eye contact with myself". He reported that the early sessions, prior to the introduction of the CymaSense intervention, facilitated an emotional outlet for participants through play, but without much interaction - "the sessions were almost like a real outlet for suppressed emotion ... without it being reciprocal". He reported that for others there was little apparent enthusiasm - “. . quite withdrawn, didn't seem to be that much energy or motivation".

He went on to mention that participants could take time becoming comfortable with unfamiliar people and environments, preventing creativity and interaction - "Lots of repetitive, ritualistic behaviours.... high anxiety". The tutor identified a way to build trust with the participants in the sessions prior to introducing the intervention - "I would sort of match or try to mirror what [P2] was doing and then gradually use that as a vehicle to create something more musical, or more creative".

The tutor commented on building a relationship with a participant to create a platform for interaction "It can take quite a long time with [P2] to trust people, be relaxed, to interact and to share". However, he went on to note that having previously worked with the majority of the participants, the familiarisation process was relatively brief - "Straight away [P6] was quite familiar and at ease".

Subsequently, the tutor identified a change in emotional state for a number of the participants once the intervention had been introduced to the study. Immediately prior to these sessions, he pointed out that "[P7 was] anticipating the new Cymatics environment and activities... gazing at the projector and screen, smiling"; "[P1] had eye contact on Cymatics table on entering the room, even when it was covered... triggering smile and laughing responses".

During the intervention sessions the tutor reported observable changes including greater enthusiasm for the sessions - "[P7 was] engaged, communicative". Immediately following the intervention sessions, the tutor suggested that participants, on the whole, were emotionally affected by a new experience - "[P7 had] a sense of having a meaningful engaged experience". "[P8 had] a creative and emotional outlet". He added that "[P1] had reduced stereotypical and repetitive behaviours"; whilst "[P4] is gradually revealing much more inventiveness, self-organisation and structure".

The tutor pointed out that during the withdrawal phase of the study on Week 11, participants missed working with the CymaSense application - "[P8] was missing the Cymatics set-up and talking about it"; "[P7] was looking for visual response when using the mic"; "[P1] was looking for the Cymatics table".

It could be inferred that by the end of the study, attitudes and behaviour had become more enthusiastic and less anxious - "[P1] [shows] instant recognition and joyful response when we meet and I cue for going to [the] music".

\subsubsection{Interface}

The second ranked code Interface (referring to accessibility and playability), had 81 instances, only three interviewees referred to it during the discussions. One interviewee (PA2) was particularly unfamiliar with technology in general, and was not comfortable responding to any of the technology-based questions with confidence. Phrases included 'non-verbal playground', 'shared space' and 'aesthetic experience'. Interviewees commented on the ways participants' attitudes differed towards technology external to, and within, the study sessions.

\section{PA1}

The interviewee commented that P4 seemed to be drawn to technology - "what you can certainly say with [P4] is that computers are just [their] thing". However, PA1 noted that the participant could tire of technology - "[They have] a Wii app, but I think [they find] it a bit boring". Nonetheless, PA1 noted a positive reaction with regards to the use of CymaSense "from the non-intervention stage to the intervention stage, when the technology came in, [they were] definitely a lot more interested". The interviewee added they would encourage other parents of people with ASC to use the intervention - "I 
would have definitely recommended this to them. I would have said to them, go and try this".

\section{PA2}

The interviewee noted that P2 was not familiar with technology - "[They're] not a technology-driven [person]".

\section{PA3}

The interviewee identified P1's use of technology - "[They] use a computer, a smartboard [they] used at school ... [they've] got [their] own little tablet". Regarding the participant's use of CymaSense, PA3 noted the recognition of the audio-visual association - "Once it clicks with [them], 'I hit this soft and it's kind of this size', or 'I hit this hard it's bigger".

PA3 also commented on other potential users of the CymaSense - "Children in [P1]'s class ... you could take it forward from there". The interviewee proposed use of the application as a speech development tool - "when [P1]'s not speaking, [their] muscles aren't being used, to see these vowels all the time, it's almost an exercise, so I think that would be good".

\section{MT}

The music tutor inferred that interaction with CymaSense was positive - "[P8] was enjoying the sense of control and independence". He suggested that CymaSense was intuitive and accessible enough not to require training for use - "there's no instructions needed". In addition, he noted that the interface is user friendly for participants - "[P4] loves, manipulating, control, and reflecting his mood with colour palette choice and shape". He identified how participants adapted the application to suit their own tastes - "they could take ownership of, rather than it being prescriptive".

The tutor mentioned some unpredictable improvisation from participants, relating to the application's playability - "lots of surprises ... being really creative with it". He commented that it had created novel experiences for participants, describing it as a "non-verbal playground", adding that it added "extra theatrical sensory dimensions to the music sessions".

The tutor implied that by using the application via the interactive table, it created a comfortable environment for participants - "I think that's so important that there was shared space". He suggested that this facilitated a greater improvisational dynamic - "...a visual field in the middle that we're interacting with... really influenced by the proximity". The tutor signified the importance of a shared activity and how it could aid in communication - "you want it to be shared...something we could talk about, not verbally, but we can play with...I think that definitely occurred".

The music tutor suggested that the aesthetic of the Cymatic shapes may have expanded the expressive potential of participants within a music session - a "great tool to widen aesthetic experience". He implied the application worked well to raise participants" awareness through the multi-modal approach - "Great tool for sensory integration".

He also commented on the effectiveness of the audio to visual mapping. He suggested that participants recognised and explored the connection between audio volume and visual scale: "you see it can be a tiny little shape that they're making, or it can be massive, so tailored to that individual".

The tutor mentioned that the application aided in creativity - "The sensitivity of the triggers led [them] to explore more subtle, meditative expressions". He also recognised successful pitch to colour associations - "[It] links in well with [P6]'s synesthesia, relating sounds, pitch to colour and sensory integration". He specified one participant's recognition of how pitch related to Cymatic shape - "[P4]'s really using pitch - 'what happens if I'm going up the scale? Oh right, what happens visually there?".

He reported that the Cymatic shapes created an interesting aesthetic that augmented the musical interaction - "the shapes and the contours lend themselves to something like melody and pitch and percussion and music". He suggested that the organic nature of Cymatics was more motivational for participants compared to other forms of music visualisation - "a lot of guys look at their frequency graph or whatever, and that's quite mathematical...but there's something really attractive and motivational, the organic element". 
The tutor also recognised potential for the application and suggested other user groups such as - "Scottish Autism, Sensatronic Lab, mainstream schools". He signified that the application worked well with the participants with ASC, "all with different sensory needs and different levels of ability", and he would be keen to use it with others - "there's a whole range of other people that I work with that I would love to introduce that". He went on to suggest customisation and gestural recognition as a means to further tailor the application for potential users - "Personalised animations, symbol palette, movement sensor applications". He suggested that input from participants could provide potential for a more meaningful interaction - "can it trigger patters or animations that have been developed by participants? I think that would be interesting".

\subsubsection{Independence}

Independence is ranked third with 51 instances, reflecting the role in having a sense of control for participants as viewed by interviewees. The majority of these comments originated from PA1 and the tutor, with references to terms like 'power', 'control' and 'meaningful' were used.

\section{PA1}

The interviewee commented on how important levels of control were for P4, through making their own choices in the sessions, and how that influenced their sense of independence - "I noticed a difference as a couple of weeks went on and [P4] was actually able to take a bit of the power [themselves] with what was happening with the machines and the volume and so on"; "this is all moving towards independence, definitely".

\section{MT}

The tutor also commented on the importance of encouraging participants to develop a sense of agency "[They initiate], the structure and the direction of the music". Subsequently, he signified how independence led to a meaningful experience for the participants - "[P7] is making these incredible patterns, which [they] alone [are] manipulating and in control of. It's almost letting them see a side of [themselves], animated up there"; "when [P1] realised that [they were] really manipulating that environment [they'd gotten] this other sensory level, sensory feedback...it was really meaningful to [them]".

The tutor identified that initial use of the application seemed to distance participants from himself - "the effect initially was... [they] became deeply engaged in the object"; "less about my interaction". However, he suggested this was a period of self-expression from which participants became more independent "there was that level of independence when [P1] was manipulating the colours by [their] beats". The tutor noted his subsequent ability to allow participants space to control the session from time to time; "I could actually withdraw my input and just watch what was going on". The music tutor recognised the effect that greater control had on creativity - "[P7] was becoming a bit more controlled, realising that the Cymatics was able to match [their] whole range of emotions and vocal expression". He reported that participants then invited him to join in once a level of control had been established - "over the weeks, [P7] certainly invited me in to become much more reciprocal... that really built up that dialogical element to the sessions". The tutor reported that some participants developed their level of self-awareness within a social context over the course of the study - "[P8] developed self-identity as a performer"; "[P5] was enjoying the sense of a defined role within the group as a leader".

\subsubsection{Audio-Visual Learning}

Fourth ranked is Audio-Visual Learning, with 44 instances. This referred to participants' aesthetic choices and included the phrases 'familiar logos', 'bright colours' and 'never forget an image'. This section presents observations on how participants' audio-visual aesthetic preferences affected their augmented therapeutic music experience. Interviewees reported on personal auditory and visual learning processes of the participants that may have influenced their use of CymaSense.

\section{PA1}

The interviewee commented on the participant's visual ability - "[P4] can walk up to something like a 
find Wally poster, just do this [finger pointing gesture] and [they] can point it out". PA1 inferred that iconic visual imagery aids the participant's memory in associating non-text based logos or signs with particular objects - "[they] never forget an image"; "[they're] also attracted by signs and car logos". Similarly, PA1 reported that exaggerated imagery is an effective way to form associations with emotions for people with ASC - "Disney's emotions were so exaggerated ... it's much easier to catch onto the emotions"; "A strong image, [they] would be attracted by".

The parent reasoned that the study participant translated audio information into visual components that may be used as a basis for learning - "Even though [they] like the sound of music, [they seem] to translate everything into visual terms...when [they're] speaking [they] say it as written, if you say to [them] say knife [they'll] say 'k"'. PA1 suggested that meaningful connections to music are facilitated via a visual element, highlighting the importance of multimodal learning - "It's got to be connected to music. [They] won't watch a Disney film, but [they'll] watch the short singalong ones that he associates with a particular song".

\section{PA2}

The interviewee commented on their child's ability for pattern recognition - "[P2] remembers everything, like [they've] got a computer in [their] head, [they sit] in the back [of the car] but [they know] exactly where you are on the road". PA2 went on to indicate the participant's preferences for visually driven problems - "[P2] also has one of those jigsaw puzzles... [they do] that quickly...sometimes [they don't] even look at it, [they] already [know]". The interviewee identifies audio-visual stimulation as being an important factor for the study participant - "Any kind of lights and sound, he's happy with it...we've got a disco light, [P2] loves to see that thing flashing about".

\section{PA3}

The parents of P1 mentioned that their child was visually driven - "[P1] is a visual learner, [they take] in a lot of the finer detail even". Similarly, they commented on the ability to solve visual problems - "[P1] is very good at puzzles, quite intricate ones as well". The interviewee also identified colour as being an important factor for participants in self-regulating their temperament - 'Bright colours, multi-colours, anything with colour [P1] loves it...coloured socks, doesn't like plain ones."; "[They seem] to be able to match colour, [they know] what goes with what". PA3 also commented on the participant's musical preferences - "He likes quite a lot of rhythm in something"; "he does the drums at paragon".

\section{MT}

The tutor commented on participants' audio-visual causality - "Bringing in that [visual] element [P1] realised, 'oh', there's another modality... [they know] the cause and effect there". He also implied that participants used colour to match their mood during sessions - "[P4] loves manipulating, controlling, reflecting [their] mood with colour palette choice...sharp contrasting primary colours"; "[P6] [likes] big and bold contrasting colours and movement". The music tutor suggested that the animated movement of the Cymatic shapes was a motivating factor for participants - "[P1] reacted very positively, it adds novelty and an extra sensory dimension to the music".

\subsubsection{Communication}

Finally, with 20 instances, Communication represented responses including 'verbally more communicative', 'high fives and eye contact', and 'sense of partnership'. Interviewees commented on how levels of stress and stability can affect the desire for participants to initiate or sustain communication.

\section{PA1}

The interviewee recognised that once the participant had established a sense of control of the situation throughout the sessions, they had a greater ability to express themselves from a verbal point of view "The day that [P4] actually started doing more, taking a bit more control and a wee bit more power, that was the day [they were] walking back there giving me this 'music room good go back...go back soon..' that was a wee milestone for me, and I'm sure that's a direct result of the sessions, it definitely is". PA1 went on to highlight that the sessions had been beneficial from a communicative perspective - "it's done [them] a lot of good and communication in general is massively changed since we've been here". The 
interviewee indicated that independence gained from increases in communication reduced the participant's need for assistance - "[P4 is] making [themselves] understood to the family now, so I feel I'm not constantly needed as an interpreter...I'm feeling a wee sense of freedom in that I'm able to take a wee step back".

\section{PA2}

Not all participants ability to communicate verbally were altered, as PA2 noted - "[P2 has] no speech whatsoever", however, they continued to communicate gesturally and via eye-contact.

\section{PA3}

The interviewee suggested that once a level of independence had been established, initiating communication seemed to come more naturally to P1. PA3 stated that the stresses of being expected to communicate verbally had a negative effect on the participant - "if you catch [them] off the cuff, [they manage] to say things quite easily and then other times you're like [P1] say that, and for [them] to think about it and that causes [them] nervousness". The interviewee added that the sessions had an effect on P4's attempts to communicate - "we did see a change in [P1], trying to be verbally more communicative".

\section{MT}

The tutor pointed out that some participants were communicating with greater vocal or verbal intensity as a result of the study - "[P4] is now responding with greater verbal communication in sessions". However, feedback also indicated participants' non-verbal appreciation of the application - "[P1] Yes, by non-verbal gestures and signs"; "[P4 was] happy to give high fives and eye contact".

From a musical perspective, he commented how interactive communication for participants had developed over the study - "[P7] has a greater capacity for shared experience and co-improvisation"; "[P5] [was] using voice and rhythm to manipulate the environment". The tutor identified that participants were open to new and shared experiences - "[P4] [showed] greater sense of partnership, communication, negotiation"; "[P2] was more open to try new things".

The tutor highlighted the ways in which the application nurtured a sense of performance within some of the participants - "[P8] was suggesting new ideas and ways of using Cymatics in a performative way"; "we did quite a lot of stuff in the last 3 or 4 weeks, where it would almost be like a performance"; "[P8] was using voice and piano to develop a sense of performance and theatre.".

\subsection{Discussion}

The results of the interviews confirm and support other studies that describe the use of multi-sensory environments, tangible user interfaces and natural user interfaces, such as the work of Cibrian and colleagues [102], which embodies the Therapeutic Instrumental Music and Performance (TIMP) technique for people with ASC. In the TIMP technique, therapists play musical instruments to help participants practice physical exercises; however, the participants themselves do not play any instruments. BendableSound was shown to be a successful way to encourage body awareness and independence in people with ASC through the use of an interactive audio-visual fabric surface. Ichinose et al. [112] integrate multisensory and gestural awareness in their Cyber Musical Instrument with Score (Cymis) system, developed as music therapy for people with ASD, that can trigger well-known songs through physical movement. Preliminary studies suggest improvements in on-task behaviours and collaboration with others, however, the system is aimed at children, restricted to pre-selected songs. Few studies, however, have focused on high functioning (HF) people on the autism spectrum, and young adults with ASC, using less traditional music interventions [7]. The National Autism Center's National Standards Project phase 2 report only list music therapy as an emerging intervention for children and adults under the age of 22, or as being an unestablished intervention for adults [38]. This could be attributed to an area of study where the lack of quantitative evidence does not provide the level of validity other areas take for granted. It is well documented in autism literature that there is limited intervention outcome regarding adults with ASC, and despite broadening the inclusion criteria for the adult literature, only 27 articles (28 studies) met criteria for inclusion in the 2015 review. The present study differs in its aim to create a multi-sensory environment more typical of a regular improvisational music therapy session, allowing adult participants options to play any instruments they desired, based on their own 
abilities and preferences.

Feedback from the interviews indicate that participants' behaviour, prior to, during and following the study sessions, was affected by a number of factors. Interviewees suggested that participants' initial behaviours, including nervousness and anxiety, led to a genuine enthusiasm within the music sessions. Observational and behavioural matching techniques employed by the tutor, allowed trust to be developed within a relatively short period of time, which allowed the tutor to gradually introduce more improvisational and musically creative ideas to develop interaction and communication. Interviewees noted how the unpredictability of a situation could adversely affect participants outside of the sessions due to their respective sensory influences. The growing familiarity of the music sessions may have aided in minimising any unwanted stimuli and increased the levels of comfort for the participants. Following a number of weeks working with the tutor and CymaSense intervention, positive behavioural changes were observed by both the music tutor and some of the participants' parents.

The expectations of parents and tutors can be an additional cause of anxiety for people on the autism spectrum, further creating behavioural problems, as shown by Pares and colleagues [31] in their MEDIATE study. Subsequently, when people with ASC are less self-conscious and express themselves more freely, confidence can build within them. It could be argued that as participant behaviour was free from the expectations of carers or parents, both the MEDIATE study and the CymaSense study displayed an increase in confident behaviours for some participants. Children interacted with a digitised large screen environment using a natural user interface approach that encouraged full body interaction, using gestural, tactile and visual modalities. There were a maximum of three sessions for participants between 5 and 35 minutes long, depending on their levels of comfort. The goals of MEDIATE focused on developing a sense of agency and enhancing non-repetitive behaviours for people with autism. Its outcomes demonstrated an increase in the levels of control of participants and suggested an increase in their observable levels of expressivity through physical movements. The present study used a combination of tactile, aural and visual modalities, over a 12-week series of 30-minute sessions. The aim of CymaSense was to encourage communicative behaviours and social interaction through musical freedom of expression and interaction. The outcomes indicate increases in musical and non-musical communicative behaviours for some of the participants, and suggest improvements in social and emotional behaviours, based on limited feedback from the questionnaire and the interviews.

Prior to the start of the study, the music tutor expressed reservations regarding the use of CymaSense, which he felt might be too distracting for some participants. Stimulus over selectivity in autism is a recognised problem where people with ASC respond to only a limited number of cues in their environment [113]. The tutor's concern related to a potential lack of engagement from a musical perspective. Initially, this seemed to be the case as some participants became so engaged with the application that they ignored the tutor for a period of time. Introductory sessions tended to be one-way emotional outlets for some participants where they were unable to interact with the tutor. However, it could be gathered from the interviews that engagement with the application encouraged independence, further developing social interaction, and then communication, for five of the eight participants. Music therapist Dallimer commented that research would be needed on the suitability of an audio-visual instrument for particular client groups [23]. She specified that in some cases the visuals might distract the client from the music, whereas in other situations the visuals may be a 'way in' to a client who was previously struggling to become engaged in the music. Evaluation of the interviews suggests that regular use of the application amongst participants develops a sense of control and independence. This in turn leads to musical exploration, which further establishes a sense of identity. This process ultimately leads to the participant becoming more aware of the potential for involvement of the music tutor. The desire of the participant to share in the audio-visual music making process translates into eye contact, gestural interactions for turn-taking or even verbalised invitations for the tutor to join in and improvise. A subsequent increase in social interaction occurs, as well as potentially lessening the need for caregiver assistance.

Neuropsychologist Damasio describes core consciousness experience as non-verbal and non-cognitive, arguing that communicating through the use of sound is more effective for music therapists working with people with ASC, than language based interventions [114]. Kim at al. suggest the process of musical attunement relies heavily upon the non-verbal and multi-modal components of music, including vocal 
and instrument exchanges, facial expressions, eye contact and synchronous movement and gestures [115]. It could be argued that CymaSense augments that non-verbal communication through its visual modality. Moreover, having a shared space between therapist and client provides a joint visual canvas where both can have equal say over its output. Group music making sessions can provide important social learning experiences through turn-taking, joint attention and empathy [116]. Kim et al. demonstrated that an autistic child could be motivated to socially interact with others using non-verbal aspects of music making including turn taking, reciprocal interactions and affect sharing [50]. CymaSense focuses on augmenting the act of creating music in a social context, where both participants and therapist skills are on the same perceived level within a shared space. Use of the intervention via the interactive table could further encourage rhythmic exploration and development of motor impairments and attention deficits [106][107]. The addition of the visual modality can foster a co-creative environment that raises awareness of the potential for music therapy through its ability to visualise any sound.

Interviewees suggested that the increased levels of participant communication related to improved comfort levels and stability within the sessions. Study participants' anxiety and personal expectations in initial sessions were reflected through lower levels of eye contact and verbal communication. It could be proposed that the increasing levels of communicative behaviours, noted in Phases 1 and 2, were attributed to the participants' levels of familiarity with the music tutor and improved levels of comfort within their surroundings. To verify this, a separate study without CymaSense would be necessary to compare the effect of the application. However, it should be noted that the music tutor, who had worked previously with all but one of the participants, concluded that the motivational factors of CymaSense were driven by the visual modality, rather than purely musical interaction.

It was reported that participants did miss the interaction with the CymaSense application during the withdrawal phase. However, it could equally be argued that its availability had become part of their new routine and its subsequent removal created a desire for its use. It is well-known that people on the autism spectrum rely on routine as a means to feel comfortable in their environment [117]. Wigram recognises that during improvisational music therapy, certain patterns can also reveal routines within participants' music making [118]. He also suggests that a balance between predictability in improvised routines and controlled flexibility in how melody and rhythm are used, can create effective interaction [119]. He goes on to highlight that it is participants' intentionality that needs to be best understood from the musical exchanges, rather than any recognised musical routines that may be immediately apparent. In the context of the use of CymaSense, once a platform for creativity has been established, the absence of the visual modality could be analogous to disturbing the predictability of that aspect of the user's musical routine.

General feedback from the interviewees seems to indicate that the audio-visual mapping, which drives the selection and animation of the Cymatic shapes, was appropriate. Interviewees identified participants' abilities in pattern recognition, and indicated that recognition of iconic shapes, such as car logos, was a strong feature amongst some participants, and that this may have aided in musical learning through association of pitch and shape. Although the shapes were of a generally abstract nature, feedback indicates an organic and identifiable quality to them, which helped facilitate interaction. They suggested that the visual feedback provided by CymaSense allowed participants to engage in collaborative music making more effectively than without visual feedback. This association could have been further strengthened through animation of iconic shapes and individual colour choice. It could be argued that if the shapes were more symbolic and identifiable, the effectiveness of the non-verbal interaction could be compromised, by relating more to language or to specific objects. It is also possible that visualisation of personalised shapes would reinforce associations from the participants' perspective and subsequently narrow the field of exploration from a musical perspective. Visualisation of recognisable shapes could remove any element of surprise and detract from the improvisational aspect of a music session by reinforcing established relationships. Previous research has shown that some autistic participants can easily identify shapes within complex patterns compared to neurotypicals [31]. It is conceivable that visually driven participants enjoyed the complexity and variety of the $3 \mathrm{D}$ shapes and the ways in which their musical input could affect the visual output in a variety of permutations. However, not having tested the application with $2 \mathrm{D}$ shapes, further research is required to fully validate the benefits of using $3 \mathrm{D}$ graphics.

Feedback suggests the use of colour was an important means of facilitating choice for the study 
participants. The repeated interaction of the user interface for some participants allowed a degree of independence through colour choice, and suggests an increase in the sense of control. Further exploration in the use of colour could increase the level of emotional expression for participants. Improvising with MIDI sensors that triggered musical notes and projected colours onto a shared floorspace, Hunt et al. recognised in a music therapy experiment, the power of multisensory audio-visual improvisation, and described the creation of a sacred space where sound and colour 'battles' took place [23]. Serret et al. [120] developed a game, designed for emotional recognition for people with ASC to play, using colour codes that are associated with specific emotions (yellow for joy, for example). Musical instruments, notes or phrases could be associated with colour in the same way in CymaSense. Colour could also be used to facilitate collaboration within versions of CymaSense, by encouraging perspective taking within participants. Parsons [121] developed a virtual reality based application designed to motivate shared behaviours, through matching of coloured blocks to achieve a shared goal. Biljman [122] designed a music and colour lighting system for people with ASD to enhance non-verbal expression of emotions. Significant effects were observed in cortical areas related to semantic processing and theory of mind, an area in which the author indicates could be key in developing audio-visual applications to encourage social interaction in people with ASD. Using CymaSense, musical collaborations can combine individual inputs into a shared space, and could encourage users to understand and attribute emotional connections made in music through the colours used by themselves and by others.

Minimal instruction was given to the music tutor prior to carrying out the intervention, implying an accessible design. It appears that the working practices of the tutor were not adversely affected by using CymaSense, as neither he nor the majority of participants were deterred from playing any of their favoured instruments. An accessible design in a future home version of CymaSense could provide a number of advantages in delivering the intervention, and in its effectiveness. Family motivated music therapy can play an important role in providing personalised interaction and in the delivery of the intervention itself, by supporting the acquisition of new social, emotional and behavioural skills, and the development of a high-quality relationship with the family [123]. Additionally, it can be more cost effective than clinical therapy, will provide a more natural environment for the people with ASC to learn and develop, and may lead to motivation and generalisation of newly acquired skills to post-therapy contexts [124][125]. An initial home version of CymaSense could be delivered through a tablet computer application, that utilises a built in microphone to detect and visualise external acoustic sounds, or a percussive synthesiser [98] to sonify interactions with the touch screen or other suitable interfaces like Launchpad [59], Skoog [60], or MIDI drum pad [126].

\section{CONCLUSIONS}

In this study, we set out to test the following hypotheses: (1) The use of CymaSense within therapeutic music sessions can lead to an increase in communicative behaviours during the sessions; (2) The use of CymaSense will lead to changes in the communicative, social and musical behaviours of the autistic participants observable by parents, care workers or tutors at the conclusion of the study. We designed and ran a series of therapeutic music sessions with eight participants over 12 weeks using CymaSense. The use of CymaSense was customised for each participant during the sessions either as: an interactive table; a two-user version with two microphones to visualise the sound of client and participant projected on to the wall; or via a single microphone to visualise any acoustic sound in the music room projected onto the wall. Phases 1 and 2 of the study have provided quantitative evidence that the use of CymaSense resulted in an increase in communicative behaviours for the majority of the autistic participants.

Although it is difficult or even impossible to gather a homogenous group of people with ASC, the design, implementation and results of the sample population in our study support the initial hypotheses that the use of an interactive audio-visual tool can improve communication for people on the autism spectrum. Qualitative data gathered through follow-up interviews conducted with parents/carers of the participants and the music tutor provided insights into the impact that the use of CymaSense had beyond the music sessions: Positive changes to the participants' behaviours at home were reported, including improved communication; The use of CymaSense was also highlighted as a means of promoting independence as well as offering a multimodal form of interaction. This evaluation of CymaSense opens up new possibilities for other sensory impaired groups. 
The CymaSense system architecture can support visualisation of any sound through 2D or 3D graphics, making customization for alternative groups simple. Future studies concerning the use of CymaSense by children and by alternative disability groups, including the hearing impaired, may promote social interaction by encouraging group play and turn taking.

TUI interventions [20] or NUI interventions [21], used in other studies, promote communication and social interaction within people with ASC. In this study, which involved eight autistic adults, four of which were non-verbal and two only exhibited limited language skills; we have demonstrated that significant improvements in communication can be observed in this group by augmenting music sessions with real-time visual feedback.

\section{ACKNOWLEDGMENTS}

The Authors would like to acknowledge the IIDI (Institute for Informatics and Digital Innovation) for their financial support, and TouchBase for their assistance in the organisation of the study. 


\section{REFERENCES}

[1] American Psychiatric Association. Diagnostic and Statistical Manual of Mental Disorders (5th ed.). 5th ed. American Psychiatric Publishing. Washington, DC. Arlington, VA.: American Psychiatric Publishing; 2013.

[2] Sharpe DL, Baker DL. Financial issues associated with having a child with autism. J Fam Econ Issues. 2007;28(2):247-64.

[3] Hanley GP, Iwata BA, Thompson RH. Reinforcement Schedule Thinning Following Treatment With Functional Communication Training. J Appl Behav Anal. 200I;34(I):17-38.

[4] Green G, Ricciardi J. Findings and conclusions: National standards project, phase 2. National Autism Center. 2015.

[5] Peters-Scheffer N, Didden R, Korzilius H, Sturmey P. A meta-analytic study on the effectiveness of comprehensive ABA-based early intervention programs for children with Autism Spectrum Disorders. Res Autism Spectr Disord [Internet]. 201I Jan;5(I):60-9. Available from: https://linkinghub.elsevier.com/retrieve/pii/SI 7509467/0000498

[6] Bredek C, Granpeesheh D, Thompson K, Matalon R. Visual and Other Sensory Modifications. In: Evidence-Based Treatment for Children with Autism [Internet]. Elsevier; 2014. p. II5-32. Available from: http://linkinghub.elsevier.com/retrieve/pii/B9780 I24II6030000069

[7] Hillier A, Greher G, Poto N, Dougherty M. Positive outcomes following participation in a music intervention for adolescents and young adults on the autism spectrum. Psychol Music [Internet]. 2012 Mar 1;40(2):201-15. Available from: http://pom.sagepub.com/cgi/doi/l0.1 177/03057356/0386837

[8] Johnston D, Egermann H, Kearney G. Innovative computer technology in music-based interventions for individuals with autism moving beyond traditional interactive music therapy techniques. Vol. 5, Cogent Psychology. 2018. p. I-18.

[9] Brown SMK. Autism and Music Therapy — Is Change Possible, and Why Music? J Br Music Ther [Internet]. $1994 \quad$ Jun 8;8(1):15-25. Available from: http://journals.sagepub.com/doi/I0.1 I77//35945759400800I05

[10] Lim H a, Draper E. The Effects of Music Therapy Incorporated with Applied Behavior Analysis Verbal Behavior Approach for Children with Autism Spectrum Disorders. J Music Ther [Internet]. 201I Dec 1;48(4):532-50. Available from: http://jmt.oxfordjournals.org/cgi/doi//0.1093/jmt/48.4.532

[I I] Pavlicevic M, O’Neil N, Powell H, Jones O, Sampathianaki E. Making music, making friends: Longterm music therapy with young adults with severe learning disabilities. J Intellect Disabil [Internet]. 2013;5-19. Available from: http://www.ncbi.nlm.nih.gov/pubmed/24I9684I

[12] Abrahams BS, Geschwind DH. Advances in autism genetics: On the threshold of a new neurobiology. Nat Rev Genet. 2008;9(5):34I-55.

[13] Porter S, Holmes V, McLaughlin K, Lynn F, Cardwell C, Braiden HJ, et al. Music in mind, a randomized controlled trial of music therapy for young people with behavioural and emotional problems: Study protocol. J Adv Nurs. 2012;68(10):2349-58.

[14] Simpson K, Keen D. Music interventions for children with autism: Narrative review of the literature. J Autism Dev Disord [Internet]. 20II Nov;4I(II):I507-14. Available from: http://link.springer.com/10.1007/s 10803-010-1 I72-y 
[15] Wheeler BL. Music Therapy Handbook [Internet]. Guilford Publications; 2015 [cited 2015 May 24]. $507 \quad$ P. Available from: https://books.google.com/books?hl=en\&lr=\&id=mfnhBQAAQBAJ\&pgis= I

[16] Ploog BO, Scharf A, Nelson D, Brooks PJ. Use of computer-assisted technologies (CAT) to enhance social, communicative, and language development in children with autism spectrum disorders. J Autism Dev Disord. 2013;43(2):30I-22.

[17] Hourcade JP, Williams SR, Miller EA, Huebner KE, Liang LJ. Evaluation of tablet apps to encourage social interaction in children with autism spectrum disorders. Proc SIGCHI Conf Hum Factors Comput Syst - CHI 'I3 [Internet]. 2013;3197-206. Available from: http://dl.acm.org/citation.cfm?doid=2470654.2466438

[18] Golan O, Baron-Cohen S. Systemizing empathy: Teaching adults with Asperger syndrome or high-functioning autism to recognize complex emotions using interactive multimedia. Dev Psychopathol. 2006;18:59|-617.

[19] Microsoft Corporation. Kinect Sensor [Internet]. 2012. Available from: https://docs.microsoft.com/en-us/previous-versions/microsoft-robotics/hh438998(v=msdn. I0)

[20] Villafuerte L, Markova M, Jorda S. Acquisition of social abilities through musical tangible user interface. In: Proceedings of the 2012 ACM annual conference extended abstracts on Human Factors in Computing Systems Extended Abstracts - CHI EA 'I2 [Internet]. 2012. p. 745. Available from: http://dl.acm.org/citation.cfm?id=22 I 2776.2212847

[21] Ringland KE, Zalapa R, Neal M, Escobedo L, Tentori M, Hayes GR. SensoryPaint: A Multimodal Sensory Intervention for Children with Neurodevelopmental Disorders. Proc 2014 ACM Int Jt Conf Pervasive Ubiquitous Comput - UbiComp 'I4 Adjun [Internet]. 20I4;(September):87384. Available from: http://dl.acm.org/citation.cfm?doid=2632048.2632065

[22] Cibrian FL, Peña O, Ortega D, Tentori M. BendableSound: An elastic multisensory surface using touch-based interactions to assist children with severe autism during music therapy. Int J Hum Comput Stud [Internet]. 2017;000:1-16. Available from: http://www.sciencedirect.com/science/article/pii/SI07I581917300757

[23] Hunt A, Kirk R, Neighbour M. Multimedia Interfaces for Music Therapy. leee Multimed. 2004; I I(3):50-8.

[24] Cappelen B, Andersson A-P. Health Improving Multi-Sensorial and Musical Environments. Proc Audio Most 2016 - AM 'I6 [Internet]. 2016;178-85. Available from: http://dl.acm.org/citation.cfm?doid=29864| 6.2986427

[25] McGowan J, Leplâtre G, McGregor I. CymaSense. In: Proceedings of the 2016 ACM Conference Companion Publication on Designing Interactive Systems - DIS 'I 7 Companion [Internet]. New York, New York, USA: ACM Press; 2017. p. 270-4. Available from: http://dl.acm.org/citation.cfm?doid=3064857.3079/59

[26] McGowan J, Grégory Leplâtre N, lain McGregor N. CymaSense: A Novel Audio-Visual Therapeutic Tool for People on the Autism Spectrum. 2017;62-71. Available from: http://delivery.acm.org//0.1 | 45/3|40000/3 |32539/p62-

mcgowan.pdf?ip=92.238.86.2 I 4\&id=3 I 32539\&acc=OPEN\&key=4D4702B0C3E38B35.4D4702 B0C3E38B35.4D4702B0C3E38B35.6D2 I 8 I 445 I IF3437\&CFID=99| 950 I05\&CFTOKEN $=798 \mid$ $8902 \& \_$acm_ $=1508854394 \_602 d d 708 \mathrm{ed} \mid 8473 \mathrm{f} 6 \mathrm{f} 6666 \mathrm{db} 23$

[27] Reichow B, Doehring P, Cicchetti D V., Volkmar FR. Evidence-based practices and treatments for children with autism. Evidence-Based Practices and Treatments for Children with Autism. 20I I. I-408 p. 
[28] Shaughnessy JJ, Zechmeister EB. Research methods in psychology. Alfred A. Knopf series in psychology. New York, NY, US: Knopf; 1985. 517 p.

[29] Centers for Disease Control and Prevention. Prevalence of autism spectrum disorder among children aged 8 years. MMWR Surveill Summ [Internet]. 2014;63(2):I-2I. Available from: http://www.ncbi.nlm.nih.gov/pubmed/2467096I

[30] Tsur E, Friger M, Menashe I. The Unique Evolutionary Signature of Genes Associated with Autism Spectrum Disorder. Behav Genet [Internet]. 2016 Nov II [cited 2017 Apr 6];46(6):75462. Available from: http://link.springer.com/10.1007/s 10519-016-9804-4

[3I] Parés N, Carreras A, Durany J, Ferrer J, Freixa P, Gómez D, et al. Promotion of Creative Activity in Children With Severe Autism Through Visuals in an Interactive Multisensory Environment. In 2005.

[32] Parsons S, Mitchell P. The potential of virtual reality in social skills training for people with autistic spectrum disorders. Vol. 46, Journal of Intellectual Disability Research. 2002. p. 430-43.

[33] Tantam D. ASPERGER'S SYNDROME. J Child Psychol Psychiatry [Internet]. 1988 May;29(3):245-55. Available from: http://doi.wiley.com/I0.III I/j. I469-76/0.1988.tb007/3.x

[34] Michaud F, Theberge-Turmel C. Mobile Robotic Toys and Autism. In: Dautenhahn K, Bond A, Cañamero L, Edmonds B, editors. Socially Intelligent Agents: Creating relationships with Computers and Robots. Kluwer Publishers; 2002. p. 125-32.

[35] Paxton K, Estay IA. Counselling people on the autism spectrum: A practical manual. [Internet]. Counselling people on the autism spectrum: A practical manual. Jessica Kingsley Publishers; 2007. Available from: http://ovidsp.ovid.com/ovidweb.cgi?T=JS\&PAGE=reference\&D=psyc5\&NEWS=N\&AN=200704903-000

[36] Fombonne E. Editorial: The rising prevalence of autism. J Child Psychol Psychiatry Allied Discip. 2018;59(7):717-20.

[37] Pellicano L, Dinsmore A, Charman T. A Future Made Together. Vol. 44. 2013.

[38] Fabri M, Andrews PCS. Human-Centered Design with Autistic University Students: Interface, Interaction and Information Preferences. 2016; Available from: https://link-springercom.ezproxy.brunel.ac.uk/content/pdf//0.1007\%2F978-3-319-40355-7_I5.pdf

[39] Sharda M, Silani G, Specht K, Tillmann J, Nater U, Gold C. Music therapy for children with autism: investigating social behaviour through music [Internet]. Vol. 3, The Lancet Child and Adolescent Health. 2019. p. 759-61. Available from: https://linkinghub.elsevier.com/retrieve/pii/S2352464219302652

[40] Kaplan RS, Steele AL. An analysis of music therapy program goals and outcomes for clients with diagnoses on the autism spectrum. J Music Ther. 2005;42(1):2-19.

[4I] Lim H a. The Effect of" Developmental Speech-Language Training through Music" on Speech Production in Children with Autism Spectrum Disorders. J Music Ther [Internet]. 2007;XLVII(I):2-26. Available from: papers://98I3c380-4a5a-426e-ab3b10e227534cf8/Paper/p5

[42] LaGasse AB. Effects of a Music Therapy Group Intervention on Enhancing Social Skills in Children with Autism. J Music Ther [Internet]. 2014 Sep 1;00(00):I-26. Available from: http://jmt.oxfordjournals.org/cgi/doi/l0.1093/jmt/thu0I 2

[43] Kern P, Aldridge D. Using embedded music therapy interventions to support outdoor play of 
young children with autism in an inclusive community-based child care program. J Music Ther. 2006;43(4):270-94.

[44] Wimpory D, Chadwick P, Nash S. Brief report: Musical interaction therapy for children with autism: An evaluative case study with two-year follow-up. J Autism Dev Disord [Internet]. 1995 Oct:25(5):54I-52. Available from: http://link.springer.com//0.1007/BF02I78299

[45] Kern P, Aldridge D. Using embedded music therapy interventions to support outdoor play of young children with autism in an inclusive community-based child care program. J Music Ther. 2006;43(4):270-94.

[46] Shore SM. The Language of Music: Working with Children on the Autism Spectrum. J Educ. 2003;183(2).

[47] Kern P, Wolery M, Aldridge D. Use of Songs to Promote Independence in Morning Greeting Routines For Young Children With Autism. J Autism Dev Disord [Internet]. 2007;37(7):12647I. Available from: http://link.springer.com/10.1007/s 10803-006-0272-I

[48] Trevarthen C. Autism, sympathy of motives and music therapy. Enfance [Internet]. 2002;54(I):86. Available from: http://www.cairn.info/revue-enfance-2002-I-page-86.htm

[49] Hillier A, Kopec J, Poto N, Tivarus M, Beversdorf DQ. Increased physiological responsiveness to preferred music among young adults with autism spectrum disorders. Psychol Music [Internet]. 2015;0305735615576264-. Available from: http://pom.sagepub.com/content/early/2015/03/31/0305735615576264.abstract

[50] Kim J, Wigram T, Gold C. The Effects of Improvisational Music Therapy on Joint Attention Behaviors in Autistic Children: A Randomized Controlled Study. J Autism Dev Disord [Internet]. 2008 Oct;38(9):1758-66. Available from: http://link.springer.com/l0.1007/s/0803008-0566-6

[5I] Mössler K, Gold C, Aßmus J, Schumacher K, Calvet C, Reimer S, et al. The Therapeutic Relationship as Predictor of Change in Music Therapy with Young Children with Autism Spectrum Disorder. J Autism Dev Disord [Internet]. 2019;49(7):2795-809. Available from: http://dx.doi.org//0.1007/s10803-017-3306-y

[52] Ulfarsdottir LO, Erwin PG. The influence of music on social cognitive skills. Arts Psychother [Internet]. 1999;26(2):8I-4. Available from: http://linkinghub.elsevier.com/retrieve/pii/SOI 9745569800064 I

[53] Pasiali V, LaGasse AB, Penn SL. The effect of musical attention control training (MACT) on attention skills of adolescents with neurodevelopmental delays: A pilot study. J Music Ther. 20I4;5I(4):333-54.

[54] Kalas A. Joint attention responses of children with autism spectrum disorder to simple versus complex music. J Music Ther [Internet]. 2012;49(4):430-52. Available from: http://www.ncbi.nlm.nih.gov/pubmed/23705346

[55] Lai G, Pantazatos SP, Schneider H, Hirsch J. Neural systems for speech and song in autism. Brain [Internet]. $2012 \quad$ Mar I; $135(3): 96 \mid-75 . \quad$ Available from: http://www.brain.oxfordjournals.org/cgi/doi//0.1093/brain/awr335

[56] Sharda M, Tuerk C, Chowdhury R, Jamey K, Foster N, Custo-Blanch M, et al. Music improves social communication and auditory-motor connectivity in children with autism. Transl Psychiatry [Internet]. 2018;8(I). Available from: http://dx.doi.org/I0.1038/s4/398-0I8-0287-3

[57] Wigram T, Gold C. Music therapy in the assessment and treatment of autistic spectrum 
disorder: clinical application and research evidence. Child Care Health Dev. 2006;32(5):535-42.

[58] Molnar-Szakacs I, Heaton P. Music: A unique window into the world of autism. Ann N Y Acad Sci. 20I2;1252(I):3|8-24.

[59] Novation. Launchpad | NovationMusic.com [Internet]. 2018. Available from: https://global.novationmusic.com/launch/launchpad\#

[60] SkoogMusic. Skoogmusic / We create music technology that lets anyone make music [Internet]. 2018 [cited 2015 Jul 3]. Available from: http://www.skoogmusic.com/

[61] Farr W, Yuill N, Raffle H. Social benefits of a tangible user interface for children with Autistic Spectrum Conditions. Autism. 2010;14(3):237-52.

[62] Schaaf RC, Miller LJ. Occupational therapy using a sensory integrative approach for children with developmental disabilities. Ment Retard Dev Disabil Res Rev [Internet]. 2005 Apr; I (2):I43-8. Available from: http://doi.wiley.com/10.1002/mrdd.20067

[63] Villaroman N, Rowe D, Swan B. Teaching natural user interaction using OpenNI and the Microsoft Kinect sensor. In: SIGITE'II - Proceedings of the 20II ACM Special Interest Group for Information Technology Education Conference [Internet]. New York, New York, USA: ACM Press; 20II. P. 227-31. Available from: http://dl.acm.org/citation.cfm?doid=2047594.2047654

[64] Taheri a. R, Alemi M, Meghdari A, PourEtemad HR, Holderread SL. Clinical Application of Humanoid Robots in Playing Imitation Games for Autistic Children in Iran. Procedia - Soc Behav Sci. 2015 Feb; 176:898-906.

[65] Tarbox J, Persicke A. Play. In: Evidence-Based Treatment for Children with Autism [Internet]. Elsevier; 2014. P. 223-4l. Available from: http://linkinghub.elsevier.com/retrieve/pii/B9780 I24II6030000I24

[66] Cibrian FL, Madrigal M, Avelais M, Tentori M. Supporting coordination of children with ASD using neurological music therapy: A pilot randomized control trial comparing an elastic touchdisplay with tambourines. Res Dev Disabil [Internet]. 2020 Nov; 106:10374I. Available from: https://linkinghub.elsevier.com/retrieve/pii/S089142222030I7/2

[67] Hailpern J. Encouraging Speech and Vocalization in Children with Autistic Spectrum Disorder. 2007.

[68] Lobo J, Matsuda S, Futamata I, Sakuta R, Suzuki K. Chimelight: Augmenting instruments in interactive music therapy for children with neurodevelopmental disorders. ASSETS 2019 - 21 st Int ACM SIGACCESS Conf Comput Access. 2019;124-35.

[69] Butter Churn. Butterchurn visualizer [Internet]. 2017 [cited 2017 Mar 14]. Available from: https://butterchurnviz.com/

[70] Soundspectrum. SoundSpectrum [Internet]. 2017 [cited 2017 Mar 14]. Available from: https://www.soundspectrum.com/

[7I] Haruki Hasegawa. Music Visualizer [Internet]. 2015 [cited 2017 Jul 19]. Available from: https://music-visualizer.h6ah4i.com/

[72] Frauenberger C, Makhaeva J, Spiel K. Blending Methods: Developing Participatory Design Sessions for Autistic Children. 2017;

[73] Lazar A, Cornejo R, Edasis C, Piper AM. Designing for the Third Hand : Empowering Older Adults with Cognitive Impairments through Creating and Sharing. Proc Des Interact Syst Conf 
(DIS'।6). 2016;1047-58.

[74] Aldridge D. Music therapy research II: Research methods suitable for music therapy. Arts Psychother. 1993;20(2):| |7-31.

[75] Geist K, Hitchcock JH. Single case design studies in music therapy: Resurrecting experimental evidence in small group and individual music therapy clinical settings. Vol. 5I, Journal of Music Therapy. 20I4. p. 293-309.

[76] Edgerton CL. The Effect of Improvisational Music Therapy on the Communicative Behaviors of Autistic Children. J Music Ther. 1994 Mar I;3I(I):3I-62.

[77] Christi Carnahan, Shobana Musti-Rao, Jody Bailey. Promoting Active Engagement in Small Group Learning Experiences for Students with Autism and Significant Learning Needs. Educ Treat Child. 2008;32(I):37-6I.

[78] Goldsmith TR, Leblanc LA. Use of Technology in Interventions for Children with Autism. J Early Intensive Behav Interv. 2004; I:166-78.

[79] Pasiali V. The Use of Prescriptive Therapeutic Songs in a Home-Based Environment to Promote Social Skills Acquisition by Children with Autism: Three Case Studies. Music Ther Perspect. 2004;

[80] Eneba. Why Play Alone? [Internet]. Eneba. 2020. Available from: https://www.eneba.com/blog/why-play-alone-here-are-the-best-split-screen-pc-games/

[8I] Cycling '74. Cycling '74 [Internet]. 2018 [cited 2016 Aug I]. Available from: https://cycling74.com/

[82] GIANNAKIS K. A comparative evaluation of auditory-visual mappings for sound visualisation. Organised Sound. 2006 Dec 17; I (3):297-307.

[83] Küssner MB. Shape, Drawing and Gesture: Cross-Modal Mappings of Sound and Music. King's College London; 2014.

[84] Reid JS. CymaScope:: Sound Made Visible [Internet]. 2008. 2018. Available from: https://www.cymascope.com/cyma_research/cyma_app.html

[85] Whitelaw M. Synesthesia and Cross-Modality in Contemporary Audiovisuals. Senses Soc. 2008;3(3):259-76.

[86] Smith SM, Williams GN. A visualization of music. In: Proceedings Visualization '97 (Cat No 97CB36155). IEEE; 1997. p. 499-503.

[87] Ciuha P, Klemenc B, Solina F. Visualization of concurrent tones in music with colours. In: Proceedings of the international conference on Multimedia - MM 'I0 [Internet]. New York, New York, USA: ACM Press; 2010. p. 1677. Available from: http://dl.acm.org/citation.cfm?doid=|87395I.1874320

[88] McGowan. Video Figure I - YouTube [Internet]. 2017 [cited 2017 Sep 5]. Available from: https://www.youtube.com/watch?v=BTWtVjPfBrg\&feature=youtu.be

[89] McGowan. Video Figure 2 - YouTube [Internet]. 2017 [cited 2017 Sep 5]. Available from: https://www.youtube.com/watch?v=rXOv6NKMjog\&feature=youtu.be

[90] McGowan. Video Figure 3 - YouTube [Internet]. 2017 [cited 2017 Sep 5]. Available from: https://www.youtube.com/watch?v=0c9lJUJhqZg\&feature=youtu.be 
[91] McGowan. Video Figure 4 - YouTube [Internet]. 2017 [cited 2017 Sep 5]. Available from: https://www.youtube.com/watch?v=EbKGC_weRGg\&feature=youtu.be

[92] Sense Scotland. TouchBase Business Centre [Internet]. 2017 [cited 2017 Feb 22]. Available from: http://www.sensescotland.org.uk/business-centre.aspx

[93] Sense Scotland. Sense Scotland [Internet]. 2019 [cited 2017 Apr 4]. Available from: http://www.sensescotland.org.uk/

[94] Scottish Autism. Scottish Autism - Autism Awareness Charity \&amp; Services for Children \&amp; Adults in Scotland [Internet]. 2017 [cited 2017 Apr 4]. Available from: http://www.scottishautism.org/

[95] Apple Inc. MacBook Pro - Apple (UK) [Internet]. 2018 [cited 2017 Feb 23]. Available from: http://www.apple.com/uk/macbook-pro/?afid=p238\%7CsbOuPsHFvdc_mtid_187079nc38483_pcrid_177734582548_\&cid=aos-uk-kwgo-mac-slid--product-

[96] Focusrite. Scarlett 2i2 | Focusrite [Internet]. 2018 [cited 2017 Feb 23]. Available from: https://uk.focusrite.com/usb-audio-interfaces/scarlett-2i2

[97] IK Multimedia US. IK Multimedia | iRig 2 - Guitar interface adapter for iPad, iPhone iPod touch, Android and Mac. [Internet]. 2017 [cited 2017 Apr 10]. Available from: http://www.ikmultimedia.com/products/irig2/

[98] Apple Inc. Impaktor - The drum synthesizer on the App Store [Internet]. 2017 [cited 2017 Apr 10]. Available from: https://itunes.apple.com/gb/app/impaktor-the-drumsynthesizer/id557824278? $\mathrm{mt}=8$

[99] Yang T-R, Wolfberg PJ, Wu S-C, Hwu P-Y. Supporting children on the autism spectrum in peer play at home and school: piloting the integrated play groups model in Taiwan. Autism. 2003;

[100] Hutchins TL, Prelock P a. Using Social Stories and Comic Strip Conversations To Promote Socially Valid Outcomes for Children with Autism. Semin Speech Lang. 2006;27(01):047-59.

[I0I] Norris C, Dattilo J. Evaluating Effects of a Social Story Intervention on a Young Girl with Autism. Focus Autism Other Dev Disabl. 1999;14(3):180-6.

[102] Cibrian FL, Pena O, Ortega D, Tentori M. BendableSound : An Elastic Multisensory Surface using Touch-based interactions to Assist Children with Severe Autism during Music Therapy. 2017;129.

[103] Johnson WD, Gibbons JD. Nonparametric Statistical Inference [Internet]. Vol. 15, Technometrics. $1973 . \quad 421$ p. Available from: http://www.jstor.org/stable//267003?origin=crossref

[104] Dimitriadis T, Smeijsters H. Autistic spectrum disorder and music therapy: theory underpinning practice. Nord J Music Ther. 201 I;20(2): 108-22.

[105] Papathomas P, Goldschmidt K. Utilizing virtual reality and immersion video technology as a focused learning tool for children with autism spectrum disorder. J Pediatr Nurs. 2017;35:8-9.

[106] Janzen TB, Thaut MH. Rethinking the role of music in the neurodevelopment of autism spectrum disorder. Music Sci. 2018; I:205920431876963.

[107] Yoo GE, Kim SJ. Dyadic drum playing and social skills: Implications for rhythm-mediated intervention for children with autism spectrum disorder. J Music Ther. 2018;55(3):340-75.

[108] Ulgado RR, Nguyen K, Custodio VE, Waterhouse A, Weiner R, Hayes G. VidCoach. Proc 12th 
Int Conf Interact Des Child - IDC 'I3 [Internet]. 2013;58I-4. Available from: http://dl.acm.org/citation.cfm?id=2485760.2485870

[109] QSR International Pty Ltd. QSR - NVivo Data Analysis Software | QSR International [Internet]. 2018 [cited $2016 \mathrm{Feb} 8$ ]. Available from: http://www.qsrinternational.com/

[110] Wagner HR, Glaser BG, Strauss AL. The Discovery of Grounded Theory: Strategies for Qualitative Research. Glaser B, Strauss AN, editors. Soc Forces [Internet]. 1968 Jun;46(4):555. Available from: http://www.amazon.com/dp/020230260I

[III] QSR International Pty Ltd. NVivo product range | QSR International [Internet]. 2017 [cited $2017 \mathrm{Nov} 7]$. Available from: http://www.qsrinternational.com/nvivo/nvivo-products

[I I2] Ichinose T, Takehara N, Matsumoto K, Aoki T, Yoshizato T, Okuno R, et al. Development of a System Combining a New Musical Instrument and Kinect: Application to Music Therapy for Children with Autism Spectrum Disorders. Int J Technol Incl Educ. 2016;Special Is(3):933-42.

[1 13] Lovaas OI, Koegel RL, Schreibman L. Stimulus Overselectivity in Autism: A Review of Research. Psychol Bull. 1979;86(6):1236-54.

[114] Damasio A. The feeling of what happens: Body and emotion in the making of consciousness. Nature. Houghton Mifflin Harcourt; 1999.

[1 15] Kim J, Wigram T, Gold C. Emotional, motivational and interpersonal responsiveness of children with autism in improvisational music therapy. Autism. 2009 Jul 17;13(4):389-409.

[1 16] Overy K, Molnar-Szakacs I. Being Together in Time: Musical Experience and the Mirror Neuron System. Music Percept. 2009 Jun I;26(5):489-504.

[1 I7] Fletcher-Watson S, Petrou A, Scott-Barrett J, Dicks P, Graham C, O'Hare A, et al. A trial of an $\mathrm{iPad}^{\mathrm{TM}}$ intervention targeting social communication skills in children with autism. Autism. 2015;

[118] Wigram T. A Method of Music Therapy Assessment for the Diagnosis of Autism and Communication Disorders in Children. 2000;

[119] Wigram T, Elefant $\mathrm{C}$. Therapeutic dialogues in music: Nurturing musicality of communication in children with autistic spectrum disorder and Rett syndrome. In: Communicative musicality: Exploring the basis of human companionship. 2009.

[120] Serret S, Hun S, lakimova G, Lozada J, Anastassova M, Santos A, et al. Facing the challenge of teaching emotions to individuals with low- and high-functioning autism using a new Serious game: a pilot study. Mol Autism. 20I4;5(I):37.

[12I] Parsons S. Learning to work together: Designing a multi-user virtual reality game for social collaboration and perspective-taking for children with autism. Int J Child-Computer Interact [Internet]. 2015;6:28-38. Available from: http://dx.doi.org//0.1016/j.ijcci.20I5.12.002

[122] Biljman K. Sensing the Music: An Audiovisual Environment for ASD Therapy. Intell Environ 2016. 2016;21:338-47.

[123] Oldfield A, Bell K, Pool J. Three families and three music therapists: Reflections on short term music therapy in child and family psychiatry. Nord J Music Ther. 20I2;2I (3):250-67.

[124] Koegel LK, Koegel RL, Harrower JK, Carter CM. Pivotal response intervention I: Overview of approach. J Assoc Pers with Sev Handicap. 1999;24(3): 174-85.

[125] Schreibman L, Koegel RL. Fostering self-management: Parent-delivered pivotal response training for children with autistic disorder. In: Hibbs ED, Jensen PS, editors. Psychosocial treatments for 
child and adolescent disorders: Empirically based strategies for clinical practice [Internet]. Washington: American Psychological Association; 1996. p. 525-52. Available from: http://content.apa.org/books/10196-000

[126] McMillen K. BopPad [Internet]. Keith McMillen Instruments. 2020. Available from: https://www.keithmcmillen.com/products/boppad/

[127] Van De Vall T. Color-Wheel-Template [Internet]. 2013 [cited 2018 Feb 6]. Available from: https://www.timvandevall.com/wp-content/uploads/2013/08/Color-Wheel-Template-02.png 


\begin{tabular}{|c|c|c|c|c|c|c|c|c|}
\hline & & $\begin{array}{l}\text { Much } \\
\text { less }\end{array}$ & $\begin{array}{l}\text { Somewhat } \\
\text { less }\end{array}$ & $\begin{array}{l}\text { Slightly } \\
\text { less }\end{array}$ & Same & $\begin{array}{l}\text { Slightly } \\
\text { more }\end{array}$ & $\begin{array}{c}\text { Somewhat } \\
\text { more }\end{array}$ & $\begin{array}{l}\text { Much } \\
\text { more }\end{array}$ \\
\hline 1 & $\begin{array}{l}\text { How often has the } \\
\text { participant responded to } \\
\text { you verbally since the first } \\
\text { session? }\end{array}$ & 1 & 2 & 3 & 4 & 5 & 6 & 7 \\
\hline 2 & $\begin{array}{l}\text { How often has the } \\
\text { participant responded to } \\
\text { you vocally since the first } \\
\text { session? }\end{array}$ & 1 & 2 & 3 & 4 & 5 & 6 & 7 \\
\hline 3 & $\begin{array}{l}\text { How often has the } \\
\text { participant maintained } \\
\text { eye contact in response to } \\
\text { you since the first session? }\end{array}$ & 1 & 2 & 3 & 4 & 5 & 6 & 7 \\
\hline 4 & $\begin{array}{l}\text { How often has the } \\
\text { participant responded to } \\
\text { you through gestures } \\
\text { since the first session? }\end{array}$ & 1 & 2 & 3 & 4 & 5 & 6 & 7 \\
\hline 5 & $\begin{array}{l}\text { How often has the } \\
\text { participant been } \\
\text { influenced by your } \\
\text { actions since the first } \\
\text { session? }\end{array}$ & 1 & 2 & 3 & 4 & 5 & 6 & 7 \\
\hline 6 & $\begin{array}{l}\text { How often has the } \\
\text { participant initiated } \\
\text { actions since the first } \\
\text { session? }\end{array}$ & 1 & 2 & 3 & 4 & 5 & 6 & 7 \\
\hline 7 & $\begin{array}{l}\text { How would you rate the } \\
\text { participant's level of social } \\
\text { interaction following } \\
\text { participation in the study? }\end{array}$ & 1 & 2 & 3 & 4 & 5 & 6 & 7 \\
\hline 8 & $\begin{array}{l}\text { How would you rate the } \\
\text { participant's level of self- } \\
\text { awareness following } \\
\text { participation in the study? }\end{array}$ & 1 & 2 & 3 & 4 & 5 & 6 & 7 \\
\hline 9 & $\begin{array}{l}\text { How would you rate the } \\
\text { participant's level of self- } \\
\text { control/emotional } \\
\text { regulation following } \\
\text { participation in the study? }\end{array}$ & 1 & 2 & 3 & 4 & 5 & 6 & 7 \\
\hline 10 & $\begin{array}{l}\text { How would you rate the } \\
\text { participant's level of } \\
\text { repetitive behaviour } \\
\text { following participation in } \\
\text { the study? }\end{array}$ & 1 & 2 & 3 & 4 & 5 & 6 & 7 \\
\hline 11 & $\begin{array}{l}\text { How would you rate the } \\
\text { participant's level of } \\
\text { happiness following } \\
\text { participation in the study? }\end{array}$ & 1 & 2 & 3 & 4 & 5 & 6 & 7 \\
\hline
\end{tabular}




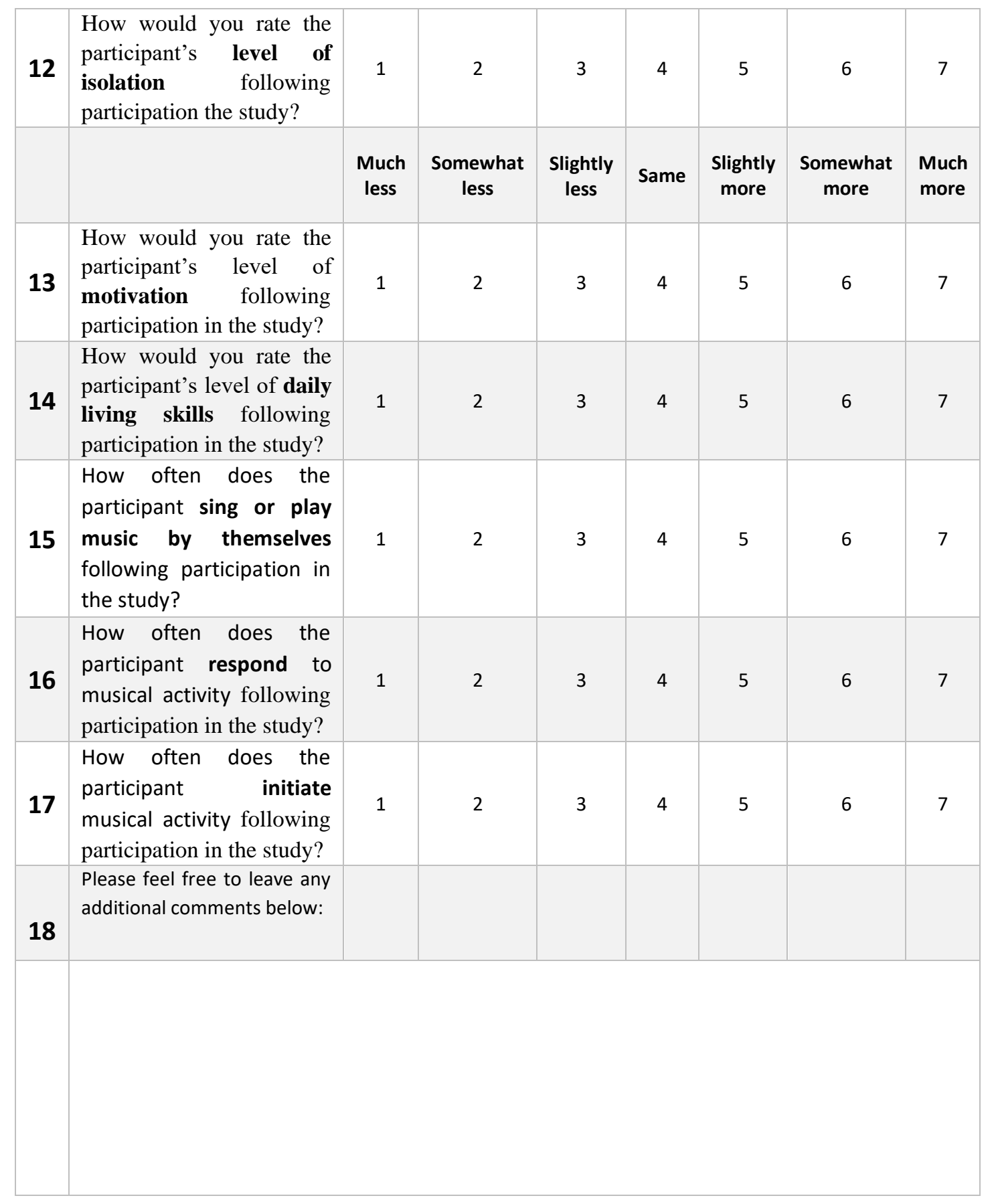


Appendix B - CymaSense Study Individual Participant and Group Graphs P1 - P6 refers to participants 1 to 6 . G1 refers to group 1.

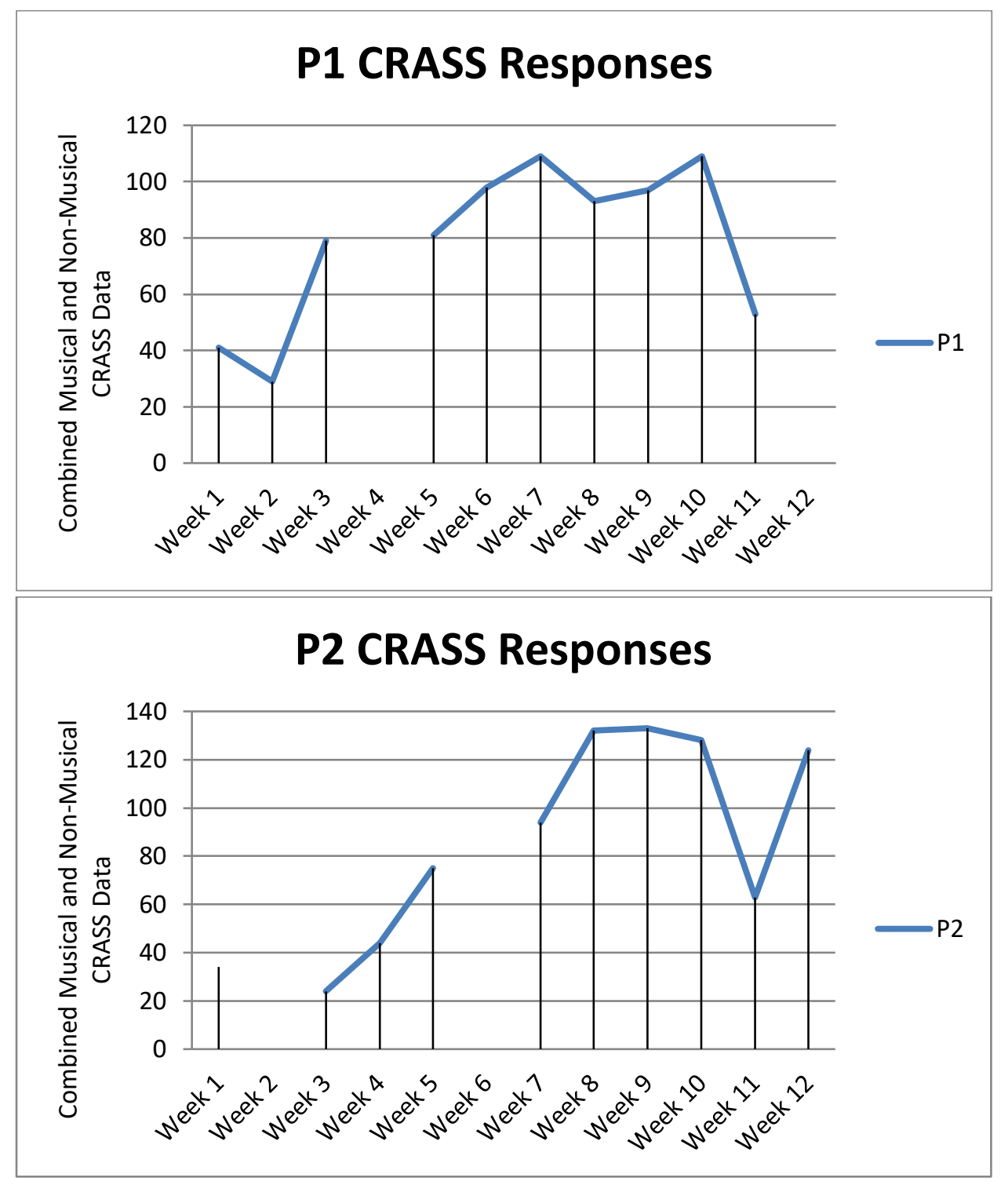




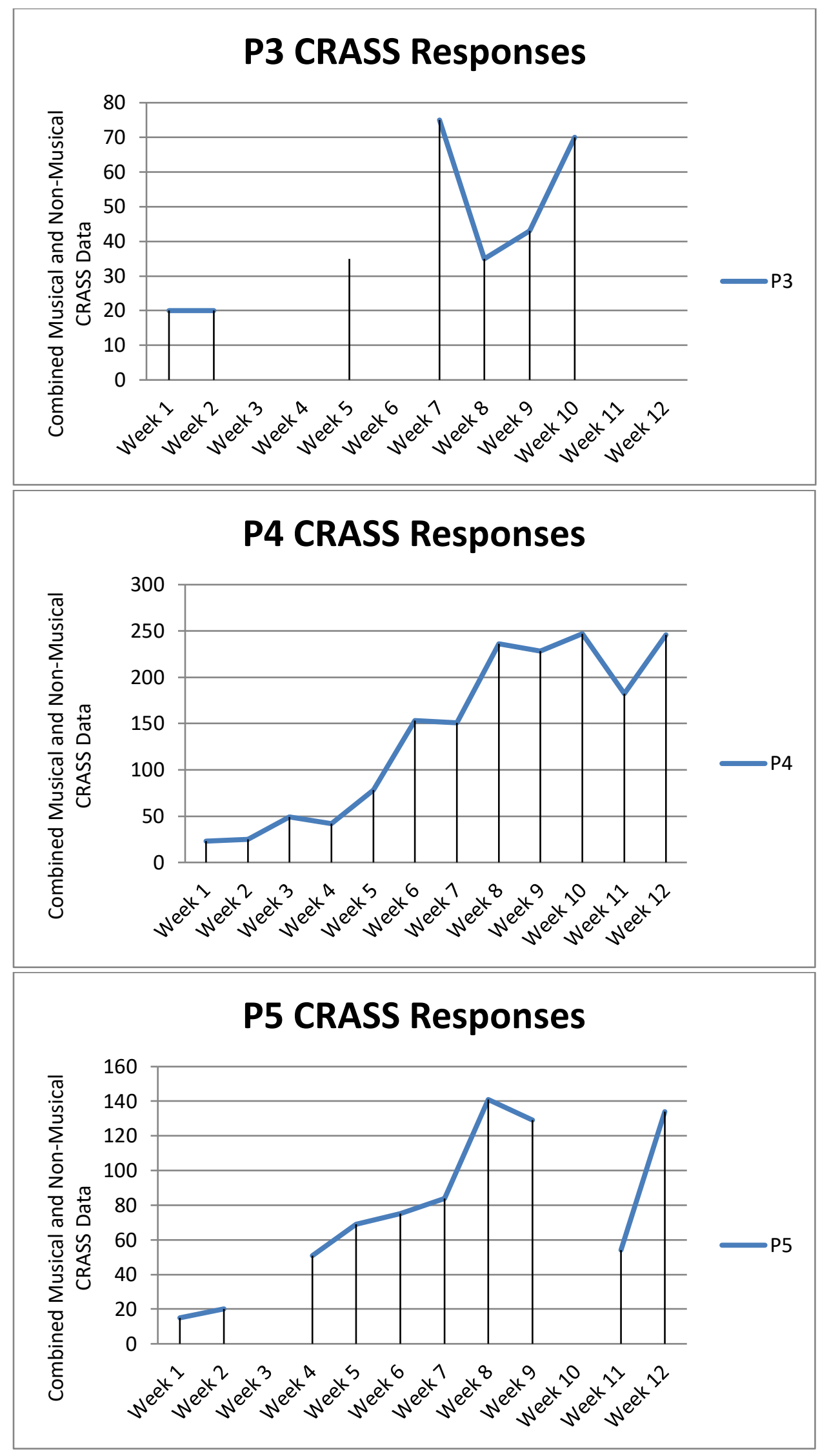




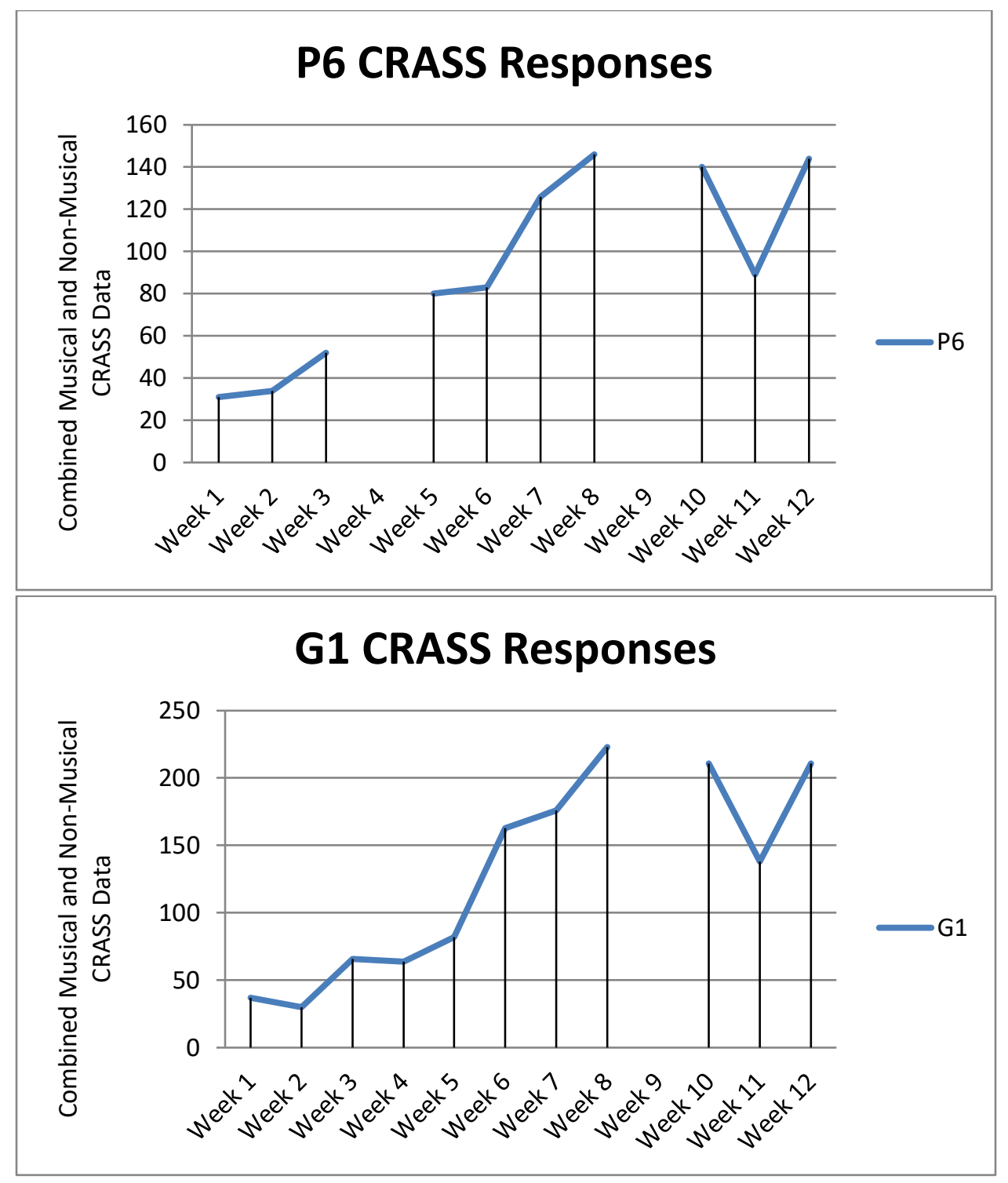


Appendix C - Phase 3 Interview Questions for CymaSense Study Participant Parents/Guardians

\section{Prior/Post Therapy}

1. What was his/her behaviour like before the sessions began?

a. Before non-intervention stage?

b. Before the intervention stages once the study was up and running?

2. What was his/her emotional state like before the sessions began?

a. Before non-intervention stage?

b. Before the intervention stages once the study was up and running?

3. What were they like immediately after the sessions?

4. Were there any signs of musical anticipation or excitement before the sessions?

5. Did you notice any short-term differences in the hours following each session?

6. Have you noticed any long term differences in the weeks after the sessions?

7. Have there been any noticeable changes in behaviour after the first 8 week block?

\section{Personal Preferences/Influences/Sensory Influences}

8. How easily distracted are they by moving objects in general?

9. How does the speed of an object, that your child sees, affect their state of mind?

10. What is their behaviour like towards technology? For example, the use of computers, screens, games?

11. What kind of image aesthetics are they drawn towards?

12. How do they react to animations?

13. Is he/she hypersensitive or hyposensitive to light, and if so, how?

14. Is he/she hypersensitive or hyposensitive to sound, and if so, how?

15. Is he/she hypersensitive or hyposensitive to touch, and if so, how?

16. How does colour affect them on a day-to-day basis?

17. Please describe any objects that can be distracting for your child in a positive or negative manner when they are in a session.

\section{Musical Preferences}

18. What type of music does they listen to at home?

19. Does this change when they are outside or away from home?

20. Do they play a musical instrument or similar at home?

\section{Technology and CymaSense}

21. What are your initial impressions?

22. What do you think doesn't work?

23. Has your child talked to you about the CymaSense tool? Can you describe which aspects?

24. Would you like to use this again?

25. Do you think others would use it? Why?

Any comments you would like to add? 
Appendix D - Behaviour Change Questionnaire Results

\begin{tabular}{|c|c|c|c|c|c|c|c|c|c|c|c|c|c|c|c|c|c|}
\hline & P1 & P2 & P3 & P4 & P5 & P6 & P7 & P8 & P9 & P10 & P11 & P12 & P13 & P14 & P15 & P16 & $\begin{array}{l}\text { Mean } \\
\text { Scores }\end{array}$ \\
\hline $\begin{array}{l}\text { Communication } \\
\text { Section } \\
\text { Mean scores for } \\
\text { section 1, } \\
\text { Questions 1-6 }\end{array}$ & 4.57 & 5.29 & 4.86 & 4.14 & 4 & 4.29 & 6.86 & 6.57 & 6.86 & 6.17 & 6.43 & 4.86 & 6.71 & 5.29 & 6.29 & 5.71 & 5.6 \\
\hline $\begin{array}{l}\text { Social/Emotional } \\
\text { Section } \\
\text { Mean scores for } \\
\text { section 2, } \\
\text { Questions 7-14 }\end{array}$ & 4.29 & 4.29 & 4.86 & 4.29 & 4.29 & 4.17 & 6.67 & 6.33 & 6.5 & 5.83 & 6.83 & 6.83 & 6.87 & 5.14 & 6.33 & 5.83 & 5.6 \\
\hline $\begin{array}{l}\text { Musical Section } \\
\text { Mean scores for } \\
\text { section 3, } \\
\text { Questions 15-17 }\end{array}$ & 4.33 & 5.33 & 5 & 4 & 5.33 & 4 & 7 & 7 & 6.5 & 6.5 & 7 & 6 & 7 & 4 & 7 & 6 & 5.7 \\
\hline
\end{tabular}

Mean scores for each respondent (P1 - P16) have been provided regarding feedback from each section. The mean scores for all respondents are included in the column on the right. 